\title{
Low Economic Class Might Predispose Children under Five Years of Age to Stunting in Ethiopia: Updates of Systematic Review and Meta-Analysis
}

\author{
Mesfin Wudu Kassaw (D), ${ }^{1}$ Aschalew Afework Bitew, ${ }^{2}$ Alemayehu Digssie Gebremariam (D), ${ }^{3}$ \\ Netsanet Fentahun $\mathbb{D},{ }^{4}$ Murat Açık $\mathbb{D},{ }^{5}$ and Tadesse Awoke Ayele $\mathbb{B}^{6}$ \\ ${ }^{1}$ Department of Nursing, College of Health Science, Woldia University, Woldia, Ethiopia \\ ${ }^{2}$ Department of Public Health, College of Health Science, GAMBY Medical College, Bahir Dar, Ethiopia \\ ${ }^{3}$ Department of Public Health, College of Health Science, Debre Tabore University, Debre Tabore, Ethiopia \\ ${ }^{4}$ Department of Nutrition and Dietetics, College of Medicine and Health Sciences, Bahir Dar University, Bahir Dar, Ethiopia \\ ${ }^{5}$ Department of Nutrition and Dietetics, Faculty of Health Sciences, Ankara University, Ankara, Turkey \\ ${ }^{6}$ Department of Public Health, College of Health Science, University of Gondar, Gondar, Ethiopia
}

Correspondence should be addressed to Mesfin Wudu Kassaw; mesfine12a@gmail.com

Received 15 June 2020; Revised 19 November 2020; Accepted 24 November 2020; Published 12 December 2020

Academic Editor: Eric Gumpricht

Copyright ( 2020 Mesfin Wudu Kassaw et al. This is an open access article distributed under the Creative Commons Attribution License, which permits unrestricted use, distribution, and reproduction in any medium, provided the original work is properly cited.

Background. Malnutrition is major public health problem worldwide, particularly in developing countries including Ethiopia. In 2016, out of 667 million children under five years of age, 159 million were stunted worldwide. The prevalence of stunting has been decreasing greatly from 58\% in 2000 to $44 \%$ in 2011 and 38\% in 2016 in Ethiopia. However, the prevalence of stunting is still high and considered as public health problem for the country. The aim of this systematic review and meta-analysis is to assess the prevalence of stunting and its associations with wealth index among children under five years of age in Ethiopia. Methodology. The databases searched were MEDLINE, Scopus, HINARI, and grey literature studies. The studies' qualities were assessed by two reviewers independently, and any controversy was handled by other reviewers using the Joanna Briggs Institute (JBI) critical appraisal checklist. The JBI checklist was used in assessing the risk of bias and method of measurement for both outcome and independent variables. Especially, the study design, study participants, definition of stunting, statistical methods used to identify the associations, results/data presentations, and odds ratios (ORs) with confidence intervals (CIs) were assessed. In the statistical analysis, the funnel plot, Egger's test, and Begg's test were used to assess publication bias. The $I^{2}$ statistic, forest plot, and Cochran's Q-test were used to deal with heterogeneity. Results. In this review, 35 studies were included to assess the pooled prevalence of stunting. Similarly, 16 studies were used to assess the estimated effect sizes of wealth index on stunting. In this meta-analysis, the pooled prevalence of stunting was $41.5 \%$ among children under five years of age, despite its considerable heterogeneity $\left(I^{2}=97.6 \%\right.$, $p<0.001, Q=1461.93)$. However, no publication bias was detected (Egger's test $p=0.26$ and Begg's test $p=0.87$ ). Children from households with a medium or low/poor wealth index had higher odds of stunting (AOR: 1.33, 95\% CI 1.07, 1.65 or AOR: 1.92, 95\% CI 1.46, 2.54, respectively) compared to children from households with a high/rich wealth index. Both of the estimated effect sizes of low and medium wealth indexes had substantial heterogeneity $\left(I^{2}=63.8 \%, p<0.001, Q=44.21\right.$ and $I^{2}=78.3 \%, p<0.001$, $Q=73.73$ ) respectively). In estimating the effect, there was no publication bias (small-studies effect) (Egger and Begg's test, $p>0.05)$. Conclusions. The pooled prevalence of stunting was great. In the subgroup analysis, the Amhara region had the highest prevalence of stunting, followed by the Oromia and Tigray regions, respectively. Low economic status was associated with stunting in Ethiopia. This relationship was found to be statistically more accurate in Oromia and Amhara regions. The government should emphasize community-based nutrition programs by scaling up more in these regions, just like the Seqota Declaration. 


\section{Background}

This is an updated systematic review and meta-analysis version which conducted with adding papers that were not included in the previous two systematic reviews and metaanalysis on the title $[1,2]$. In addition, the current systematic review and meta-analysis allow omitting of papers that were included in the previous two systematic reviews and metaanalysis but conducted before a long time $[1,2]$. The culture, and socioeconomic status of the Ethiopian community were changing over time, particularly, 2010 was the time in which the Ethiopian economy starts to grow radically [3]. In addition, 2010 was the beginning of the Growth and Transformation Plan I (GTP I) of Ethiopia [4].

Because of such reasons, authors do not allow papers that conducted before 2010. In contrary, the ending period to include studies was 2019, which was the ending period for GTP II [5]. Thus, the aim of this systematic review and metaanalysis was to measure the pooled prevalence of studying during the GTP 1 (2010-2015) [4] and GTP II (2015-2019) [5] of the country. Although the major reasons to update the review are stated, the previous two reviews were also had limitations that might affect the conclusion of their findings. One of the previous systematic reviews conducted by Ahmed et al. [1] focused on pooled prevalence of stunting, wasting, underweight, and its determinants. The other systematic review was conducted by Kalkidan and Tefera that reported determinates of stunting, wasting, and underweight [2]. Both of these systematic reviews and meta-analysis considered more than 3 outcome variables, which makes the data handling, searching strategy, and data analysis more complex. The relative stability of stunting [6] independent of the improvement of food consumption in Ethiopia [7] is the other reason to update the title despite the presence of these two systematic reviews with limitations. Despite the description to update the former systematic review, malnutrition is remained as a major public health problem in developing countries, including Ethiopia, all over the world [8]. Unfortunately, children and women are the most vulnerable population for malnutrition globally [9], and in Ethiopia [7]. In 2010, globally stunting affected approximately 162 million children under the age of 5 years [10]. In 2016, out of 667 million children, 159 million were stunted and 50 million were weakened all over the world [11]. Together with its high prevalence, malnutrition causes physical and mental developmental retardation and drop off the economic growth [12]. Worldwide, a huge gross domestic product (GDP) is lost annually due to stunting alone [13]. Stunting has also long-term effects on individual and societal health which includes diminished cognitive development, reduced productive capacity, poor health, and increased risk of degenerative diseases $[14,15]$. The prevalence of stunting reaches its peak between 12 and 24 months of childhood age $(40 \%-54 \%)$, continues to increase until 36 months of age (58\%), and then remains fairly stable until 5 years of age (55\%) [16]. According to the World Health
Organization (WHO) report, the prevalence of stunting decreased between 2000 and 2016 [17, 18]. The relative stability of stunting, its high prevalence, its severe complications, and chronic clinical features are the reasons to select it for systematic review over wasting or underweight which are usually the acute types of malnutrition with treatable complications [19].

Of the repeatedly reported factors of stunting, inadequate nutrition and repeated occurrence of infection during the first 1000 days of a child's life were the major determinants [20-24]. Birth weight, birth interval, maternal occupation, residence, food security, source of drinking water, dietary diversity, vitamin-A supplementation, type of feeding, duration of exclusive breastfeeding, wealth index, and time of initiation of complementary feeding also associated with stunting [21-34] in global perspectives. In Ethiopia, duration of breastfeeding, maternal working status, maternal education, vitamin-A supplementation, family size, monthly income, paternal education, birth weight, antinatal care (ANC) visits, maternal height, maternal body mass index (BMI), birth order, and dietary diversity associated with stunting [35-43]. Thus, updating the pooled prevalence of stunting and estimating the effect of wealth index on stunting is crucial to formulate interventions.

\section{Objective}

The objective of this systematic review is to assess the pooled prevalence of stunting and measure the estimated effect of wealth index on stunting among children under five years of age in Ethiopia.

\section{Methods}

3.1. PROSPERO Registration. The protocol had been registered in the PROSPERO (registration number CRD42019127005). PROSPERO is an international database of prospectively registered systematic reviews in health and social care. Key features from the review protocol are recorded and maintained as a permanent record. Systematic reviews should be registered at inception to help avoid unplanned duplication and to enable comparison of reported review methods with what was planned in the protocol.

3.2. Searching Strategies. We conducted a systematic and exhaustive search of literature studies published between 2010 and 2019. We assumed that the socioeconomic status of the country in the past 10 years might have not significant differences. Thus, the articles that published in the past 10 years might be homogeneous and provide more precise data against the current socioeconomic status of the nations. Designing comprehensive search strategy was a priori, in which the search term was developed using Boolean operators and adapted to databases. The databases or online libraries used were MEDLINE, Scopus, HINARI, Google 
Scholar, and Google. The searches for unpublished studies were done from institutional libraries and research gate. All searches were limited to the English language and publication dates between 01 January 2010 and 15 November 2019. The searching strategy used in MEDLINE was composed of $(((()((()((($ Child $)$ OR infant $)$ OR children $)$ OR preschool children) OR under five years children) AND wealth index) OR wealth quintiles) OR economic status) AND stunting) OR malnutrition) OR nutritional status) OR growth failure) OR chronic malnutrition) AND Ethiopia).

\section{Inclusion and Exclusion Criteria}

4.1. Inclusion Criteria. Observational studies (cross-sectional, analytical cross-sectional, case-control, cohort, and comparative observational) with one of the following criteria were included:

(i) Studies done on under-five-year-old children

(ii) Articles published only using the English language

(iii) Studies that published between 01 January 2010 and 15 November 2019 and reported a stunting prevalence or wealth index as factors of stunting

(iv) Studies that reported two prevalence values or odds ratios because of their nature of design were also included

4.2. Exclusion Criteria. However, studies with one of the following criteria were excluded:

(i) Studies using nonobservational study design

(ii) Articles with no full text or data that were difficult to extract the odds ratio, despite contacting the corresponding author(s)

(iii) Studies carried out in healthcare facilities, as illness greatly affected the nutritional status of the study participants

(iv) Studies with methodological limitations, such as incorrect outcome ascertainment criteria

(v) Studies that measured the outcome variable (stunting) other than Z-score

4.3. Measurement of the Outcome Variable and Study Variables. Since stunting is a century's burden of Ethiopia and has serious complications, we prefer it over wasting or underweight. Stunting is defined as having a height-for-age Z-score $(H A Z)<-2$ SDs for a child's age and gender. Stunting is the impaired growth and development that children experience from poor nutrition, repeated infection, and inadequate psychosocial stimulation. It is classified as a $\mathrm{HAZ}<-2 \mathrm{SDs}$, a measure based on comparisons of a child's height $(\mathrm{cm})$ and age (months) to WHO standards [44]. Wealth index is a composite measure of a household's living standard that is separated into five quintiles.

It is calculated using the ownership of a household's selected assets (rural or urban), such as televisions and bicycles, materials used for housing construction, types of water access, and sanitation facilities [45]. In this review, the wealth index was categorized into three quintiles (low/poor, medium, and high/rich) from the primary studies that reported the wealth index using five categorized quintiles: poorest, poorer, medium, richer, and richest as per the EDHS recommendation [45]. The poorest and poorer wealth indices were grouped into low/poor, medium wealth index into medium, and the richer and richest wealth indices into high/rich.

4.4. Study Selection and Data Collection. The studies identified through the database searches were combined, exported, and managed using Endnote version X9.2 software (Thomson Reuters, Philadelphia, PA, USA). Duplicated studies were removed, and the full texts of the articles were searched by Endnote software. Three reviewers (AA, AD, and MW) assessed the studies for eligibility independently. These authors are senior lectures and took a systematic review and meta-analysis training for one year. Two of the authors ( $\mathrm{AD}$ and $\mathrm{MW}$ ) have more than 10 publications including systematic review and meta-analysis articles. The reviewers assessed papers starting with the title, abstract, and then full text. The discrepancies between these three reviewers were solved by discussion with other reviewers (TA, MA, and NF). These three authors were senior researchers. Two of the authors (TA and NF) have more than 50 publications including systematic review and meta-analysis. Also, they are trainers of systematic reviews and metaanalysis.

4.5. Quality Assessment of Individual Studies. The JBI checklist was used in assessing the risk of bias and method of measurement for both outcome and independent variables. Especially, the study design, study participants, definition of stunting, statistical methods used to identify the associations, results/data presentations, and odds ratios (ORs) with confidence intervals (CIs) were assessed. The retrieved studies were assessed based on their designs using the JBI checklist for cross-sectional studies [46], case-control studies [47], and cohort studies [47]. With regard to the critical appraisal process, studies that got 5 out of 8 for cross-sectional, 6 out of 11 for cohort, and 5 out of 10 for case control were considered to have good quality/low risk. Studies that have scores below the cut points in the JBI checklist were considered as poor quality/high risk. All the authors were involved in appraising the quality of articles. A single article was assessed by two authors, and when there was controversy, a third author reviewed the paper.

The teams arranged for the critical appraisal were MW \& AA, TA \& NF, and AD \& MA. However, when the disagreement happened, any of these authors from any of the team was assigned. The decision made based on the evaluation of the third author. If they rejected the article, they also mentioned the reason of rejection. In addition, the existence of publication bias was assessed using funnel plots and symmetry. Egger's test was also computed [48] to confirm the subjective assessment. In 
Egger's test, a $p$ value of $<0.05$ was used to declare the presence of a statistical significance publication bias.

4.6. Data Extraction and Management. The data extraction sheet was piloted using nine papers that were selected randomly. Findings of the prevalence section $(\mathrm{P})$ and its associations with wealth index (OR) from each study were summarized by all authors using Microsoft Excel. The teams of authors to extract the data were MW \& AA, TA \& NF, and $\mathrm{AD} \& \mathrm{MA}$. Finally, the extracted Excel data were merged together. When there is a discrepancy between the two authors within the team, a third author was assigned and managed the disagreement. Any mistyping of data and other concerns were resolved through crosschecking with the included papers. The data extraction format was prepared by all the authors through the assistance of the Joanna Briggs Institute (JBI) data extraction tool for prevalence and incidence and associations studies. From each study, the authors, year of publication, study design, sample size, outcome, anthropometric analysis, prevalence of stunting and its standard error, and wealth index estimates with its standard error were extracted. Electronic mails were sent to the corresponding or first authors of the studies or abstracts for missing information, and we waited 3 to 4 weeks for their responses. When there were no responses, the papers were excluded with the reason that the papers were not available.

4.7. Statistical Analysis. The extracted data were exported to STATA/SE version 14.0 software for analysis. The pooled prevalence of stunting and its associations with wealth index were determined by the random effect model using DerSimonian-Laird weighting [49]. Since the studies retrieved were heterogeneous by study area, sample size, design, population, and study period, we decided to use the random effect model. Our statement is also concurrent with evidence that heterogeneity in meta-analysis is mostly known to be inevitable due to differences in study quality, sample size, method. and different outcomes measured across studies $[50,51]$. The statistical heterogeneity was checked by forest plot subjectively and Cochran's Q-test and $I^{2}$ statistic [52] objectively.

In order to minimize the variance of point estimates between primary studies, a subgroup analysis was carried out. When the heterogeneity was consistent, sensitivity analysis was used to determine the effect of each study on the pooled prevalence. The presence of publication bias (small study effect) was also checked using graphical tests (funnel plots) and the objective tests, Egger's test [48], and Begg's test. Both Egger's and Begg's tests were statistically significant $(p<0.05)$, indicating the presence of a small study effects. Whenever there was publication bias, it was handled by nonparametric trim and fill analysis using the random effect model [53].

\section{Results}

5.1. Literature Searches and Selections. In the initial search, 1642 records were found from the electronic databases. The databases searched and their records found from were MEDLINE (1059), Scopus (175), Google Scholar (236), HINARI (110), and grey literature studies [54, 55]. The grey literature studies considered in this review were Google Search, Research gate, Google Scholar, and institutional repository. Of the 1642 papers, only 828 papers remained for further evaluation after removing duplicates. Upon the appraisal of the titles and abstracts, 323 records were excluded. There were 58 full-text articles that were eligible for critical appraisal. However, 18 records were further excluded for not fulfilling the inclusion criteria. Finally, 39 articles remained for this review and meta-analysis $[25,26,42,55-90]$. Of these 39 studies, 35 of the studies were used in assessing the pooled prevalence of stunting $[25,26,42,55-62,64,65,67-81,83,84,86,88-91]$, and 16 of the studies were used to estimate the effect of wealth index on stunting $[55-57,65,70,73,76,77,79,80,82,83,85-88]$ (Figure 1). Of the 16 papers that used to estimate the effect of wealth index on stunting, four were not used in calculating the pooled prevalence of stunting [82, 83, 85, 87].

5.2. Characteristics of the Studies. The pooled prevalence of stunting was computed using 35 studies that gave 51,452 children aged birth to 5 years old. The sample size of those primary studies ranged from 214 to 9893 under-five children. Of the sample children for the review, 24,107 had the outcome of stunting, or and wealth index $[25,26,42,55-62,64,65,67-81,83,84,86,88-91]$. Only one study was conducted at a health facility [25], whereas the remaining 34 studies were conducted at the household level. All the studies considered in the pooled prevalence of stunting were studied using cross-sectional design. Eight of the papers were published from 2010 to $2014[61,65-67,73,76,77,79]$, and the remaining 31 papers were published from 2015 to 2019. Three of the studies were conducted from Ethiopian demography health and survey (EDHS) data $[62,85,91]$, and two of the papers were studied using secondary data $[25,61]$. Five of the studies considered children aged 6-24 months $[56,57,67,70,82]$, and one study considered children aged 24 to 59 months old [59]. However, all the other studies were conducted on children aged 6 to 59 months old. Nine studies were from Amhara $[26,42,65,76,79,80,84,86,89]$ and SNNP regions $[55,58,60,67,73,75,78,82,83]$. Studies from Oromia Region $(n=7)$ [25, 56, 59, 66, 71, 77, 87], Tigray $\operatorname{Region}(n=3)$ [64, 69, 70], Somalia Region, Ethiopia $(n=2)[57,74]$, Benishangul-Gumz Region $(n=1)$ [88], and Afar Region $(n=2)$ [68, 81], and six studies were nation-based [61, 62, 72, 85, 90, 91] (Table 1).

Three of the studies did not report the sex of the study population, children $[66,67,86]$, but all the other studies reported the sex of children. Accordingly, boys contributed to $65.2 \%(33,533)$ of the study population (Table 1$)$.

Most papers were published in a peer-reviewed journal. However, only one study [88], and one mini demography and health survey (EDHS) report [90] fulfilled the criteria and included in this systematic review and meta-analysis. 


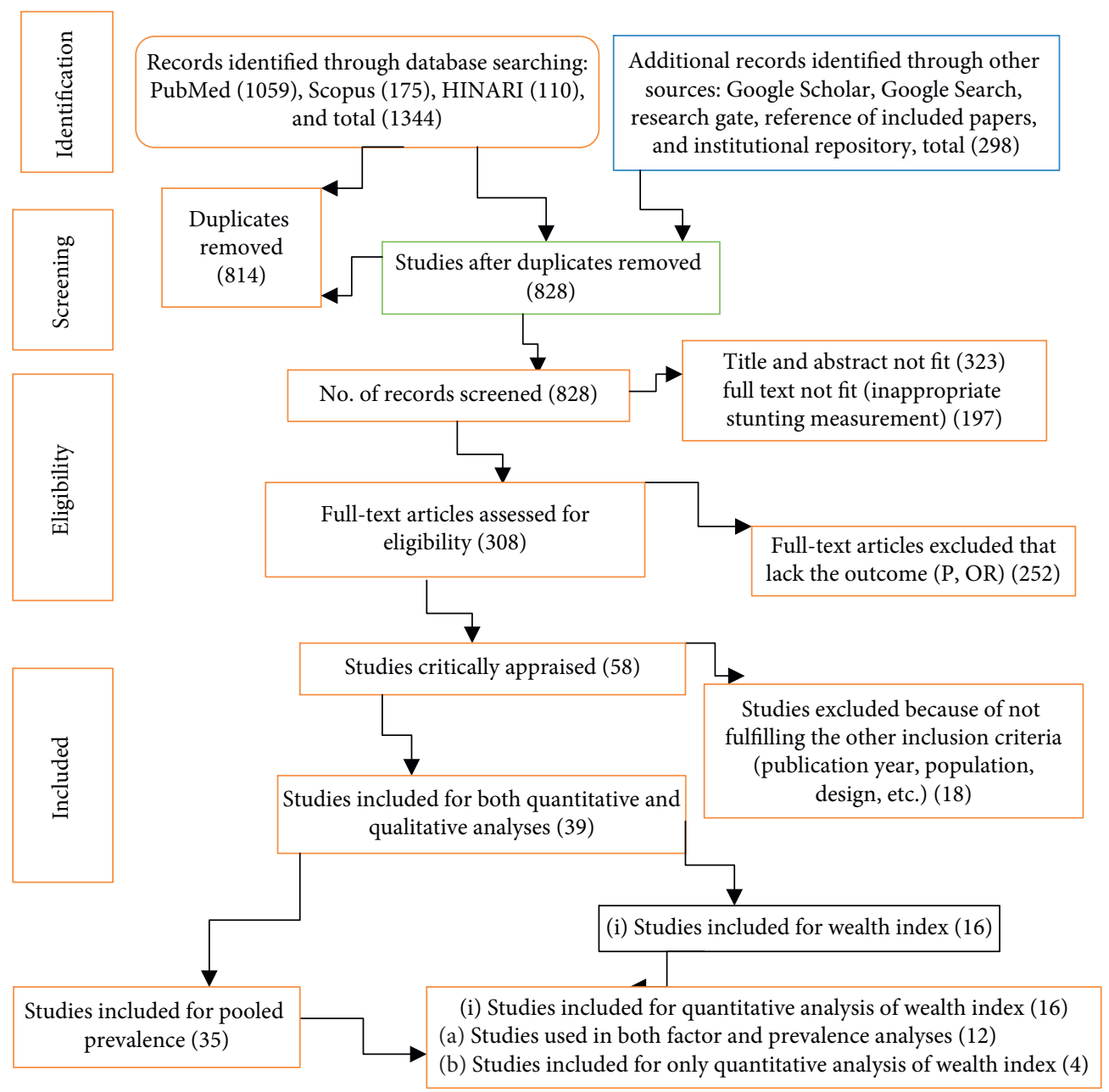

FIgURE 1: The PRISMA flowchart that indicates study selection and appraisal process.

Regarding the associations between wealth index and stunting, the sample size of the studies was 22,183 children aged birth to 5 years. With regard to the effect estimation of the associations, the sample size ranged from 214 to 7452 participants. All the studies that used to estimate the effect sizes of wealth index on stunting were conducted at household level [55-57, 65, 70, 73, 76, 77, 79, 80, 82, 83, 85-88]. Considering this associations between stunting and wealth index, one of the papers studied used a cohort design [87], two of the papers studied used case-control design [70, 82], and the remaining 13 studies studied used cross-sectional design. Six of the studies $[65,76,79,80,82,86]$ were from Amhara Region, three were from South Nations, Nationalities, and Peoples' Region (SNNPR) [55, 73, 83], three were from Oromia Region [56, 77, 87], one was from Tigray Region [70], one was from Somalia Region [57], and one was from Benishangul-Gumuz Region [88], while one study was a nation-based study (Ethiopia) [85] (Tables 1 and 2).

More important descriptions for this review came from a study by Behailu et al. that used a comparative crosssectional design and reported two prevalence values and two odds ratios (OR). Thus, we considered this paper as two papers in the meta-analysis section, but it was cited only once. Therefore, the data on the pooled magnitude of stunting were generated from 36 [76] studies, and the pooled estimate of the wealth index was produced using 17 studies [76], but the number of citations was indicated as 35 and 16 for the pooled prevalence and effect estimate, respectively. Therefore, all the forest plots have one additional paper than the papers mentioned in the PRISMA chart.

5.3. Systematic Review. The prevalence of stunting from each primary studies varied from $18.7 \%$ to $64.5 \%$ (Figure 2 ).

Most of the studies (33 studies) included were from seven regions of Ethiopia, and 6 were country-based studies $[61,62,72,85,90,91]$. The highest numbers of studies were reported from Amhara Region, nine of the prevalence studies $[26,42,65,76,79,80,84,86,89]$, and six of the wealth index studies $[65,76,79,80,82,86]$, while the lowest number of studies were from Benishangul-Gumuz Region, only one study was included in the prevalence section [88]. Considering the associations between the wealth index and stunting, there was one study for each region, including Tigray Region, Ethiopia [70], Somalia Region, Ethiopia [57], 
TABLE 1: Summary of included studies in assessing prevalence and associated factors of stunting in Ethiopia, 2010-2019 [68-82].

\begin{tabular}{|c|c|c|c|c|c|c|c|c|}
\hline Author & $\mathrm{P} /$ year & Region & Study setting & Study design & Data source & Sample size & Outcome & Reference \\
\hline Abay et al. & 2019 & Ethiopia & Community based & Cross sectional & Primary & 9495 & Stunting & [63] \\
\hline Abdibari et al. & 2016 & Somalia & Community based & Cross sectional & Primary & 694 & Stunting & [74] \\
\hline Abel et al. & 2017 & Afar & Community based & Cross sectional & Primary & 840 & Malnutrition & [68] \\
\hline Ahmed et al. & 2015 & Oromia & Community based & Cross sectional & Primary & 453 & Stunting & [59] \\
\hline Amare et al. & 2010 & SNNP & Community based & Cross sectional & Primary & 2410 & Stunting & [73] \\
\hline Amare et al. & 2017 & Amhara & Community based & Cross sectional & Primary & 1295 & Stunting & [80] \\
\hline Amare et al & 2016 & Amhara & Community based & Cross sectional & Primary & 681 & Stunting & [84] \\
\hline Araya et al. & 2017 & Tigray & Community based & Cross sectional & Primary & 610 & Malnutrition & {$[64]$} \\
\hline Atanaw et.al & 2018 & Amhara & Community based & Cross-sectional & Primary & 593 & Undernutrition & [86] \\
\hline Bealu et al. & 2017 & SNNP & Community based & Cross sectional & Primary & 508 & Nutritional status & {$[60]$} \\
\hline Behailu et al & 2014 & Amhara & Community based & Cross sectional & Primary & 367 & Malnutrition & [76] \\
\hline Behailu et al. & 2014 & Amhara & Community based & Cross sectional & Primary & 620 & Malnutrition & [76] \\
\hline Birara et al. & 2014 & Amhara & Community based & Cross sectional & Primary & 844 & Stunting & [79] \\
\hline Demewoz et al. & 2016 & NA & Community based & Cross sectional & EDHS & 11,872 & Stunting & {$[62]$} \\
\hline Dilano & 2018 & Benishangul & Community based & Cross sectional & Primary & 564 & Stunting & [88] \\
\hline Disha et al. & 2013 & NA & Community based & Cross sectional & Secondary & 3422 & Undernutrition & {$[61]$} \\
\hline EDHS & 2019 & Ethiopia & Community based & Cross sectional & Primary & 4989 & Stunting & [90] \\
\hline Eskeziaw et al. & 2015 & SNNP & Community based & Cross sectional & Primary & 567 & Stunting & [78] \\
\hline Hiwot et al. & 2017 & SNNP & Community based & Cross sectional & Primary & 834 & Undernutrition & [75] \\
\hline Hiwot et al. & 2012 & Oromia & Community based & Cross sectional & Primary & 791 & Undernutrition & {$[66]$} \\
\hline Jalane & 2019 & Oromia & Community based & Cross sectional & Primary & 616 & Chronic undernutrition & {$[71]$} \\
\hline Kalkidan & 2017 & Oromia & Community based & Cross sectional & Primary & 584 & Wasting \&stunting & {$[56]$} \\
\hline Kasahun et al. & 2019 & NA & Community based & Cross sectional & EDHS & 8743 & Stunting & [91] \\
\hline Kebede et al. & 2013 & Oromia & Community based & Cross sectional & Primary & 820 & Malnutrition & [77] \\
\hline Kidanemariam et al. & 2016 & Tigray & Community based & Case control & Primary & 330 & Stunting & [70] \\
\hline Lamrot et al. & 2018 & SNNP & Community based & Cross sectional & Primary & 398 & Stunting & [58] \\
\hline Masresha et al. & 2011 & SNNP & Community based & Cross sectional & Primary & 575 & Stunting & {$[67]$} \\
\hline Misgan et al. & 2016 & Afar & Community based & Cross sectional & Primary & 401 & Stunting & {$[81]$} \\
\hline Samson et al. & 2019 & SNNP & Community based & Cross sectional & Primary & 342 & Stunting & [83] \\
\hline Seifu et al & 2017 & SNNP & Community based & Cross sectional & Primary & 3975 & Stunting & [55] \\
\hline Selamawit et al. & 2015 & Amhara & Community based & Cross sectional & Primary & 1287 & Stunting & [26] \\
\hline Shiferaw et al. & 2018 & Amhara & Community based & Cross sectional & Primary & 410 & Stunting & [42] \\
\hline Taye et al. & 2018 & Oromia & Community based & Cohort & Primary & 4468 & Stunting & {$[87]$} \\
\hline Terefe et al. & 2017 & SNNP & Community based & Case control & Primary & 587 & Stunting, \& wasting & {$[82]$} \\
\hline Tesfaye et al. & 2019 & Tigray & Community based & Cross sectional & Primary & 394 & Stunting & [69] \\
\hline Wagaye et al. & 2014 & Amhara & Community based & Cross sectional & Primary & 610 & Undernutrition & {$[65]$} \\
\hline Yeshalem & 2017 & Amhara & Community based & Cross sectional & Primary & 480 & Undernutrition & [89] \\
\hline Yirgu et al. & 2015 & Somalia & Community based & Cross sectional & Primary & 210 & Nutritional status & {$[57]$} \\
\hline Zemenu et al. & 2017 & Oromia & Facility based & Cross sectional & Secondary & 384 & Malnutrition & [25] \\
\hline Zufan et al. & 2019 & Ethiopia & Community based & Cross-sectional & EDHS & 7452 & Nutritional status & [85] \\
\hline
\end{tabular}

Note. NA: not applicable; SNNPR: South Nations, Nationalities, and Peoples' Region; EDHS: Ethiopian Demographic and Health Survey.

and Benishangul-Gumz Region, Ethiopia [88], and there was one nation-based study (country-wide) [85]. The highest prevalence of stunting was reported from Amhara Region (64.5\% [80] and 60.6\% [76], followed by the Oromia region (61.1\%) [59], whereas the lowest prevalence was from the SNNP region (18.7\%) [78], followed by the Somalia region (22.9\%) [57] (Table 1). The highest odds of stunting because of low economic class were reported from Tigray (AOR 6.0) [70] and Oromia (AOR 4.5 and 3.3) [56, 77]. Similarly, the highest odds of stunting because of having a medium economic class were from SNNP (AOR 2.5) [83], Tigray (AOR 2.4) [70], and Oromia (AOR 2.3) [77].

5.4. Meta-Analysis. Thirty-five studies were included to assess the pooled prevalence of stunting $[25,26,42,55-62,64,65,67-81,83,84,86,88-91]$. On the other hand, 16 studies were used to estimate the pooled effect sizes of wealth index on stunting
$[55-57,65,70,73,76,77,79,80,82,83,85-88]$. The procedure we followed while including, excluding, appraising, and extracting papers was presented in the Preferred Reporting Items for Systematic Reviews and Meta-Analyses (PRISMA) flowchart (Figure 1) [92].

5.5. Prevalence of Stunting in Ethiopia. The pooled prevalence of stunting in Ethiopia was 41.5\% (95\% CI: 38.65, 44.34), despite a considerable heterogeneity $\left(I^{2}=97.6 \%\right.$ and $p<0.001)$. Cochran's Q-test and $I^{2}$ statistics, as well as forest plot and Galbraith plot, were considered to deal with this high degree of heterogeneity. The Galbraith plot indicated that more than 26 of the points or studies were outside of the $95 \% \mathrm{CI}$, and the CIs were not overlapping on the forest plot (Figure 2).

5.6. Heterogeneity Deal. The heterogeneity among studies in assessing prevalence among 35 studies by region was quite high. The $I^{2}$ statistics varied from $89.4 \%$ at Somalia 
TABLE 2: The main findings and quality assessment reports of the selected studies conducted from 2010 to 2019 about stunting in Ethiopia.

\begin{tabular}{lllcl}
\hline Author & Year Male Age & $\begin{array}{c}\text { Anthropometric } \\
\text { analysis }\end{array}$ & Confounding adjusted & Main findings
\end{tabular}

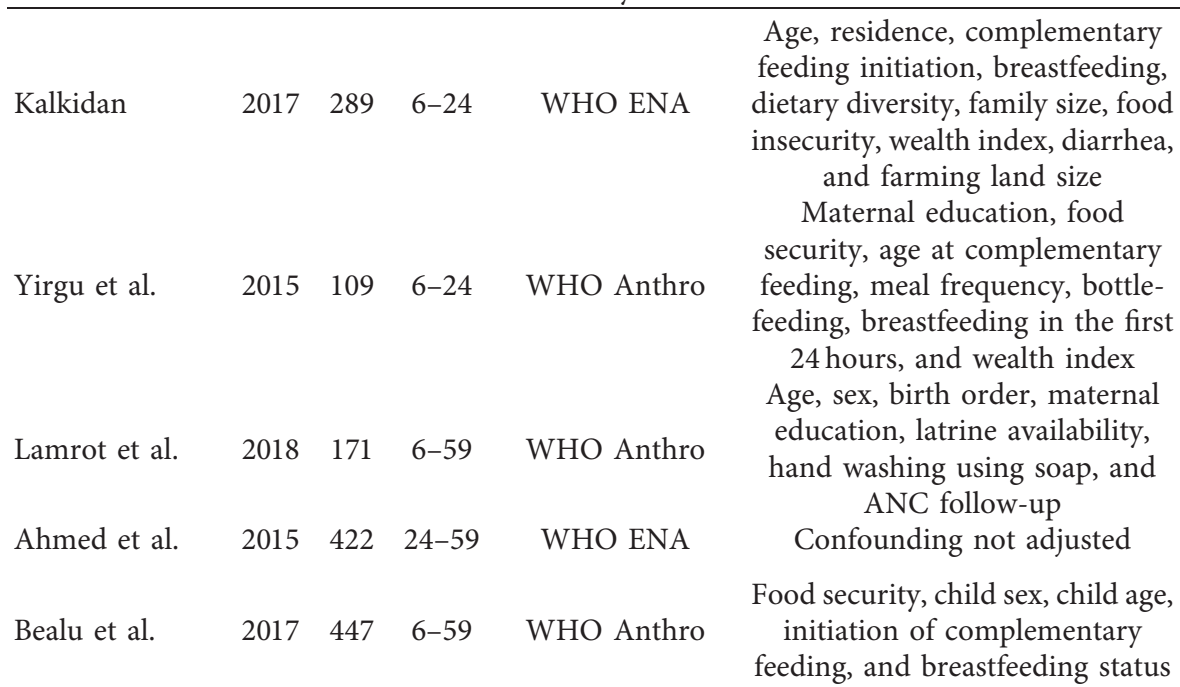

Disha et al. $2013 \quad 1783 \quad 6-59 \quad$ NAv $\quad$ Food insecurity

Seifu et al $\quad 2017 \quad 1969 \quad 6-59 \quad$ WHO Anthro

Demewoz et al. $2016 \quad 6168 \quad 6-59$

Kasahun et al. $2019 \quad 4455 \quad 6-59$

Araya et al. $\quad 2017 \quad 326 \quad 6-59$

WHO Anthro

Selamawit et al. $2015 \quad 622 \quad 6-59 \quad$ WHO ENA

Wagaye et al. $2014 \quad 399 \quad 6-59 \quad$ WHO ENA

Hiwot et al. 2012 NAv 6-59 WHO Anthro
Age of the child, sex of the child, morbidity, place of delivery, maternal education, ethnicity/ race, and household wealth index

Child age, sex, anemia, maternal age, maternal education, birth interval, family size, wealth index, place of residency, region, and source of drinking water

Child age, birth interval, wealth index, maternal education, source of drinking water, mothers body mass index, and child sex

Mothers hand washing, cleaning material used to wash hands, source of drinking water, and age of child

Morbidity, age of child, number of family size, marital status, father's education, and occupational status of house hold head

Child age, monthly income, ANC follow-up, family size, prelacteal feeding, and maternal age at first birth

Residence, number children, age of child, birth order, mothers' BMI, and source of drinking water
Child caring practices are

independent predictors of

nutritional status than wealth or economic indicators

Low dietary diversity scores, inappropriate age of

complementary feeding initiation, Low

and bottle-feeding were predictors of stunting

$41.7 \%$ of child was stunted. Age, sex, birth order, mother education, having toilet facility, and ANC

follow-up associated with stunting

$61.1 \%$ of children were stunted

$45.6 \%$ were stunted. Household

food insecurity, child age, and

initiation of complementary

feeding associated with stunting

$50.7 \%$ of children were stunted.

Household food insecurity associated with stunting

$43.7 \%$ of children were stunted.

Age and sex were associated with stunting. Advanced maternal education and house hold food

security were protective factors of stunting

$44.4 \%$ of children were stunted.

Birth interval, sex of the child, sex of household head, anemia, maternal education, father's

education, poverty, and maternal nutritional status

Not breastfeeding children, children from poor households, male children, and short birth spacing associated with stunting.

$36.1 \%$ of children were stunted.

Age is the only factor associated Low with stunting

$49.4 \%$ of children were stunted. Age of the child, number of family size, and father's educational status associated with stunting

$57.7 \%$ of children were stunted.

Prelacteal feeding and age at first birth associated with stunting.

Monthly family income was inversely associated with stunting $45.8 \%$ of children were stunted. Number of children, age of the child, birth order, and mother's BMI associated with stunting 
TABle 2: Continued.

\begin{tabular}{|c|c|c|c|c|c|c|c|}
\hline Author & Year & Male & Age & $\begin{array}{c}\text { Anthropometric } \\
\text { analysis }\end{array}$ & Confounding adjusted & Main findings & $\begin{array}{l}\text { Risk } \\
\text { (JBI) }\end{array}$ \\
\hline Masresha et al. & 2011 & NAv & $6-24$ & WHO Anthro & $\begin{array}{l}\text { Extra food during pregnancy and } \\
\text { lactation, prelacteal feeding, } \\
\text { bottle-feeding, meal frequency, } \\
\text { and dietary diversity }\end{array}$ & $\begin{array}{l}37.2 \% \text { of children were stunted. } \\
\text { Time of complementary food } \\
\text { started and extra food during } \\
\text { pregnancy and lactation associated } \\
\text { with stunting }\end{array}$ & Low \\
\hline Abel et al. & 2017 & 476 & $6-59$ & WHO Anthro & $\begin{array}{l}\text { Sex of child, age of child, time of } \\
\text { complementary food started, } \\
\text { child immunization status, } \\
\text { diarrheal disease in the last } 2 \\
\text { weeks, fever in last } 2 \text { weeks, and } \\
\text { presence of latrine in the house }\end{array}$ & $\begin{array}{c}43.1 \% \text { of children were stunted. Sex } \\
\text { of child, age of the child, diarrhea in } \\
\text { the last two weeks, and fever in the } \\
\text { last two weeks associated with } \\
\text { stunting }\end{array}$ & High \\
\hline Tesfaye et al. & 2018 & 172 & $6-59$ & WHO ENA & $\begin{array}{l}\text { Sex of the child, marital status, } \\
\text { mother education, mother } \\
\text { occupation, extra food during } \\
\text { lactation, and hand washing } \\
\text { facility near to toilet }\end{array}$ & $\begin{array}{c}49.2 \% \text { of children were stunted. Sex } \\
\text { of the child and hand washing } \\
\text { facility near to toilet associated with } \\
\text { stunting }\end{array}$ & Low \\
\hline $\begin{array}{l}\text { Kidanemariam } \\
\text { et al. }\end{array}$ & 2016 & 164 & $6-24$ & NAv & $\begin{array}{l}\text { Maternal education, mother } \\
\text { height, birth weight, number of } \\
\text { children under five, dietary } \\
\text { diversity, mother BMI, repeated } \\
\text { previous illness, age at } \\
\text { complementary feeding, and } \\
\text { household income }\end{array}$ & $\begin{array}{l}\text { Maternal education, mother height, } \\
\text { birth weight, number of children, } \\
\text { dietary diversity, mother BMI, and } \\
\text { repeated previous illness were } \\
\text { associated factors of stunting }\end{array}$ & High \\
\hline Jalane Mekonen & 2019 & 306 & $6-59$ & WHO Anthro & $\begin{array}{c}\text { Fever in the last } 2 \text { weeks, diarrhea } \\
\text { in the last } 2 \text { weeks, age at } \\
\text { complementary food started, } \\
\text { duration of exclusive } \\
\text { breastfeeding, and number of } \\
\text { children }\end{array}$ & $\begin{array}{l}\text { Stunting was associated with } \\
\text { mother educational status, number } \\
\text { of children, age of complementary } \\
\text { foods started, and presence of } \\
\text { diarrhea in the last two weeks }\end{array}$ & Low \\
\hline Hiwot et al. & 2017 & 432 & $6-59$ & WHO ENA & $\begin{array}{l}\text { Age of mothers, colostrum } \\
\text { feeding, exclusive BF in the first } \\
\text { six months, cessation of } \\
\text { breastfeeding status, diarrheal } \\
\text { morbidity in the past } 12 \text { months, } \\
\text { and sex of the child }\end{array}$ & $\begin{array}{c}39.3 \%, 15.8 \% \text { and } 6.3 \% \text { of children } \\
\text { were stunted, underweighted and } \\
\text { wasted respectively. Male child, not } \\
\text { fed on colostrums, cessation of } \\
\text { breastfeeding before two years of } \\
\text { age, and diarrheal morbidity in the } \\
\text { last } 12 \text { months associated with } \\
\text { stunting }\end{array}$ & Low \\
\hline Behailu et al. & 2014 & 330 & $6-59$ & WHO ENA & $\begin{array}{l}\text { Sex of Head of HH, family size, } \\
\text { ANC visits, child sex, domestic } \\
\text { animals, colostrum feeding, EBF, } \\
\text { measles sickness, latrine, } \\
\text { protected water, birth order, } \\
\text { presence of bed, child diarrhea, } \\
\text { and monthly income }\end{array}$ & $\begin{array}{l}\text { The prevalence of stunting, } \\
\text { underweight, and wasting was } \\
60.6 \%, 31.1 \% \text {, and } 12.6 \% \text { in the } \\
\text { community-based nutrition } \\
\text { program implementing districts, } \\
\text { respectively }\end{array}$ & High \\
\hline Behailu et al. & 2014 & 192 & $6-59$ & WHO ENA & $\begin{array}{l}\text { Sex of Head of } \mathrm{HH} \text {, family size, } \\
\text { ANC visits, child sex, colostrum } \\
\text { feeding, EBF, measles sickness, } \\
\text { presence of bed, child diarrhea, } \\
\text { and monthly income }\end{array}$ & $\begin{array}{l}\text { The prevalence of stunting, } \\
\text { underweight, and wasting was } \\
39.0 \%, 27.5 \% \text {, and } 14.7 \% \text { in } \\
\text { noncommunity-based nutrition } \\
\text { program implementing districts, } \\
\text { respectively }\end{array}$ & High \\
\hline Kebede et al. & 2013 & 410 & $6-59$ & WHO ENA & $\begin{array}{l}\text { Sex, age, and educational status of } \\
\text { mothers, family monthly income, } \\
\text { ownership of farm land, } \\
\text { gestational age, use of family } \\
\text { planning, and time to obtain } \\
\text { drinking water }\end{array}$ & $\begin{array}{l}47.6 \%, 30.9 \% \text {, and } 16.7 \% \text { of } \\
\text { children were stunted, underweight } \\
\text { and wasted, respectively. Child age, } \\
\text { family monthly income, prelacteal } \\
\text { feeding, and family planning } \\
\text { associated with stunting }\end{array}$ & Low \\
\hline
\end{tabular}


TABle 2: Continued.

\begin{tabular}{|c|c|c|c|c|c|c|c|}
\hline Author & Year & Male & Age & $\begin{array}{c}\text { Anthropometric } \\
\text { analysis }\end{array}$ & Confounding adjusted & Main findings & $\begin{array}{l}\text { Risk } \\
\text { (JBI) }\end{array}$ \\
\hline Birara et al. & 2014 & 435 & $6-59$ & WHO ENA & $\begin{array}{c}\text { Sex of child, age of child in } \\
\text { months, breastfeeding status, and } \\
\text { wealth quintile }\end{array}$ & $\begin{array}{l}\text { The prevalence of stunting, } \\
\text { underweight, and wasting was } \\
47.3 \%, 25.6 \% \text {, and } 8.9 \% \text { ( } 95 \% \mathrm{CI} \text { : } \\
\text { 6.9-10.2), respectively. Age of the } \\
\text { child, sex of the child, and } \\
\text { breastfeed status associated with } \\
\text { stunting }\end{array}$ & Low \\
\hline Amare et al. & 2017 & 656 & $6-59$ & WHO ENA & $\begin{array}{l}\text { Wealth status, maternal } \\
\text { education, maternal employment } \\
\text { status, paternal education, health } \\
\text { care access, source of drinking } \\
\text { water, availability of latrine, } \\
\text { breastfeeding initiation, } \\
\text { complementary feeding } \\
\text { initiation, and dietary diversity } \\
\text { score }\end{array}$ & $\begin{array}{c}37.7 \% \text { and } 26.8 \% \text { were moderately } \\
\text { and severely stunted, respectively. } \\
\text { Farming occupation of mother, } \\
\text { lack of postnatal vitamin-A } \\
\text { supplementation, poorer } \\
\text { household wealth status, and } \\
\text { accessing family food from farms } \\
\text { were determinants of severe } \\
\text { stunting }\end{array}$ & Low \\
\hline Shiferaw et al. & 2018 & 228 & $6-59$ & WHO ENA & $\begin{array}{l}\text { Birth order, birth interval, birth } \\
\text { weight, immunization status, } \\
\text { diarrhea, method of feeding, age } \\
\text { of child, duration of } \mathrm{BF} \text {, and } \\
\text { complementary food started }\end{array}$ & $\begin{array}{l}\text { Low weight at birth, older age, } \\
\text { mistimed initiation of } \\
\text { complimentary feeding, and } \\
\text { mothers' lack of ANC visit } \\
\text { associated with stunting }\end{array}$ & Low \\
\hline Misgan et al. & 2016 & 178 & $6-59$ & WHO ENA & $\begin{array}{l}\text { Sex of the child, ANC visit, } \\
\text { minimum dietary diversity, } \\
\text { household hunger scale, } \\
\text { prelacteal feeding, maternal age, } \\
\text { and monthly household income }\end{array}$ & $\begin{array}{c}32.2 \%, 23.5 \% \text {, and } 13.8 \% \text { of } \\
\text { children were stunted, } \\
\text { underweight, and wasted, } \\
\text { respectively }\end{array}$ & Low \\
\hline EDHS & 2019 & 1298 & $6-59$ & NAv & Confounding not adjusted & $\begin{array}{c}37 \% \text { of children were stunted. The } \\
\text { prevalence of stunting was } 22 \% \\
\text { among children } 6-8 \text { months and } \\
44 \% \text { on children aged } 48-59 \\
\text { months }\end{array}$ & Low \\
\hline Abay et al. & 2019 & 3637 & $6-59$ & NAv & $\begin{array}{l}\text { Age of the child, region, mother's } \\
\text { education, mother's BMI, wealth } \\
\text { index, sex, size of child, and } \\
\text { number of children }\end{array}$ & $\begin{array}{l}\text { Child age, maternal education, } \\
\text { region, wealth status, religion, sex } \\
\text { of child, number of children, child } \\
\text { size, water access, and toilet facility } \\
\text { were factors of stunting }\end{array}$ & High \\
\hline Amare et al & 2010 & 974 & $6-59$ & NAv & $\begin{array}{l}\text { Age of mother, sex, birth order, } \\
\text { and family income }\end{array}$ & $\begin{array}{l}\text { There is no association between } \\
\text { malaria and undernutrition } \\
\text { Factors contributing to }\end{array}$ & Low \\
\hline Abdibari et al. & 2016 & 232 & $6-59$ & WHO ENA & $\begin{array}{c}\text { Family size, educational status of } \\
\text { mothers, occupations of mothers, } \\
\text { income, child sex, and availability } \\
\text { of latrine in the house }\end{array}$ & $\begin{array}{l}\text { malnutrition were immunization } \\
\text { status, family size, child sex, } \\
\text { monthly income, maternal } \\
\text { education, and total duration of } \\
\text { breastfeeding }\end{array}$ & Low \\
\hline Eskeziaw et al. & 2015 & 273 & $6-59$ & WHO Anthro & $\begin{array}{l}\text { Residence, sex, age of mother, } \\
\text { maternal education, occupational } \\
\text { status, media exposure, place of } \\
\text { delivery, ANC follow-up, PNC } \\
\text { follow-up, and maternal illness }\end{array}$ & $\begin{array}{l}\text { Stunting associated with child sex, } \\
\text { ANC follow-up, maternal illness } \\
\text { after delivery, maternal literacy, } \\
\text { and occupation }\end{array}$ & Low \\
\hline Zemenu et al & 2017 & 80 & $6-59$ & NAv & $\begin{array}{l}\text { Child age, sex, and maternal } \\
\text { education }\end{array}$ & $\begin{array}{l}38.3 \% \text { of children were stunted. } \\
\text { Only maternal education was } \\
\text { associated with stunting }\end{array}$ & High \\
\hline Atanaw et.al. & 2018 & NAv & $6-59$ & WHO Anthro & $\begin{array}{l}\text { Mothers' occupation, number of } \\
\text { under-five children, decision } \\
\text { making, age of children, and } \\
\text { wealth index }\end{array}$ & $\begin{array}{l}\text { The prevalence of stunting and } \\
\text { wasting were } 42.3 \% \text { and } 7.3 \% \text {, } \\
\text { respectively. Poor wealth status and } \\
\text { age of child associated with } \\
\text { stunting. }\end{array}$ & Low \\
\hline
\end{tabular}


TABLE 2: Continued.

\begin{tabular}{|c|c|c|c|c|c|c|c|}
\hline Author & Year & Male & Age & $\begin{array}{c}\text { Anthropometric } \\
\text { analysis }\end{array}$ & Confounding adjusted & Main findings & $\begin{array}{l}\text { Risk } \\
\text { (JBI) }\end{array}$ \\
\hline Zufan et al. & 2019 & 3816 & $6-59$ & NAv & $\begin{array}{l}\text { Sex of the child, age of the child, } \\
\text { residence, region, family size, } \\
\text { maternal educational status, } \\
\text { source of drinking water, wealth } \\
\text { index, birth order, and place of } \\
\text { delivery }\end{array}$ & $\begin{array}{l}\text { Maternal education and maternal } \\
\text { nutritional status associated with } \\
\text { stunting. Similarly, maternal } \\
\text { nutritional status, place of delivery, } \\
\text { and birth interval associated with } \\
\text { wasting }\end{array}$ & Low \\
\hline Terefe et al. & 2017 & 569 & $6-24$ & WHO Anthro & $\begin{array}{l}\text { Maternal education, wealth } \\
\text { status, main source of family } \\
\text { food, source of drinking water, } \\
\text { availability of latrine, dietary } \\
\text { diversity, and child age }\end{array}$ & $\begin{array}{l}\text { The prevalence of stunting and } \\
\text { wasting was } 58.1 \text { and } 17.0 \% \text {, } \\
\text { respectively. Poor wealth status, } \\
\text { child age of } 12-24 \text { months, and } \\
\text { source of family food of own food } \\
\text { production associated with } \\
\text { stunting }\end{array}$ & Low \\
\hline Samson et al. & 2019 & 164 & $6-59$ & WHO Anthro & $\begin{array}{l}\text { Child sex, child age, maternal } \\
\text { educational status, monthly } \\
\text { income, use of family planning, } \\
\text { distance to obtain drinking water, } \\
\text { family size, and prelacteal feeding }\end{array}$ & $\begin{array}{l}\text { The prevalence of stunting was } \\
24.9 \% \text { with } 7.9 \% \text { of severely } \\
\text { stunted. Children aged } \\
\text { 12-23 months old, children with } \\
\text { diarrheal morbidity, and children } \\
\text { who received prelacteal feeding } \\
\text { were predictors of stunting }\end{array}$ & Low \\
\hline Taye et al. & 2018 & 1419 & $6-59$ & WHO ENA & $\begin{array}{l}\text { Sex of child, age of child, malaria } \\
\text { infection, height for age, wealth } \\
\text { status, and maternal education }\end{array}$ & $\begin{array}{l}44.9 \text { of children were stunted. } \\
\text { Children with malaria and younger } \\
\text { age were more likely to be stunted. } \\
\text { Stunting and wasting were not risk } \\
\text { factors of malaria }\end{array}$ & Low \\
\hline Dilano Abdisa & 2018 & 311 & $6-59$ & WHO Anthro & $\begin{array}{c}\text { Sex of child, duration of } \\
\text { breastfeeding, family size, } \\
\text { paternal education, and paternal } \\
\text { occupation }\end{array}$ & $\begin{array}{l}32.8 \% \text { of children were stunted. } \\
\text { Family size, low dietary diversity } \\
\text { score, duration of breastfeeding, } \\
\text { and sex of children associated with } \\
\text { stunting }\end{array}$ & High \\
\hline Amare et al & 2016 & 365 & $6-59$ & WHO ENA & $\begin{array}{c}\text { Colostrums, family size, source of } \\
\text { household food, and dietary } \\
\text { diversity }\end{array}$ & $\begin{array}{l}\text { The prevalence of stunting was } \\
46 \% \text {. Latrine facility and family size } \\
\text { associated with stunting }\end{array}$ & Low \\
\hline $\begin{array}{l}\text { Yeshalem } \\
\text { Mulugeta }\end{array}$ & 2017 & 248 & $6-59$ & WHO ENA & $\begin{array}{l}\text { Marital status, occupation, } \\
\text { possession of radio, child's living } \\
\text { situation, number of children, } \\
\text { illness, prelacteal feeding, and } \\
\text { initiation of complimentary } \\
\text { feeding }\end{array}$ & $\begin{array}{l}\text { The prevalence of stunting, } \\
\text { underweight, and wasting was } 42 \% \text {, } \\
22.1 \% \text {, and } 6.4 \% \text {, respectively. } \\
\text { Illness in the preceding two weeks, } \\
\text { having two children under the age } \\
\text { of three, and late initiation of } \\
\text { complementary feeding associated } \\
\text { with stunting }\end{array}$ & Low \\
\hline
\end{tabular}

Note. WHO ENA: World Health Organization Emergency Nutrition Assessment; WHO Anthro: WHO Anthro Survey Analyser; NAv: not available; JBI: Joanna Briggs Institute.

Region to $98.6 \%$ at the country-based studies. The prevalence of stunting (from the lowest to the highest magnitude of stunting) was $28.4 \%$ in Somalia Region, $32.8 \%$ (single study prevalence) in Benishangul-Gumuz Region, $36.4 \%$ in South Nations, Nationalities, and Peoples' Region (SNNPR) of Ethiopia, 37.7\% in Afar Region, $40.1 \%$ at the country-based study (Ethiopia), $42.5 \%$ in Tigray Region, $43.5 \%$ in Oromia Region, and $48.2 \%$ in Amhara Region, with considerable high heterogeneity. The heterogeneity of the prevalence estimates among the subgroups of 35 studies on stunting by population of the study was also very high. The $I^{2}$ statistics for children $\leq 2$ years old (6 to 24 months) was $93.0 \%$, while it was $97.6 \%$ for children less than 5 years old (6 to 59 months old). The prevalence of stunting among children $\leq 2$ years old ( 6 to 24 months) was $28.16 \%$ (95\% CI: 18.83, 37.48), while it was $42.68 \%$ (95\% CI: $39.78,45.59)$ among children $<5$ years old.

5.7. Sensitivity. Sensitivity analysis was performed using 26 studies by removing data from the meta-analytic model in order to examine the influence of studies with low quality or high bias on the pooled prevalence of stunting. After 10 studies removed due to being highly biased, the prevalence became $43.19 \%$ (95\% CI: 42.62, 43.76, $I^{2}=97.3 \%$, and Cochran's $Q=927.85)$. This sensitivity analysis prevalence was put within the $95 \% \mathrm{CI}$ of the pooled magnitude of stunting (41.5\%) (95\% CI: 38.65, 44.34, $I^{2}=97.6 \%$, and Cochran's $Q=1461.93)$. Thus, the sensitivity analysis assured 


\begin{tabular}{|c|c|c|c|c|}
\hline Author & Year & & ES $(95 \%$ CI) & $\begin{array}{c}\text { Weight } \\
(\%)\end{array}$ \\
\hline Lamirot & 2018 & $\rightarrow-$ & $41.70(36.80,46.60)$ & 2.69 \\
\hline Bealu & 2017 & - & $45.60(41.29,49.91)$ & 2.74 \\
\hline Zemenu & 2017 & $\rightarrow \frac{1}{1}$ & $38.30(33.40,43.20)$ & 2.69 \\
\hline Kebede & 2013 & $\leftarrow$ & $47.60(44.27,50.93)$ & 2.81 \\
\hline Eskezyiaw & 2015 & $\leftarrow$ & $18.70(15.56,21.84)$ & 2.82 \\
\hline AmareT2. & 2017 & + & $64.50(61.95,67.05)$ & 2.85 \\
\hline Shiferaw & 2018 & $1 \rightarrow$ & $52.40(47.30,57.50)$ & 2.67 \\
\hline Yeshalem & 2017 & $\rightarrow$ & $42.00(37.49,46.51)$ & 2.72 \\
\hline Samson & 2019 & $\rightarrow-$ & $24.90(20.39,29.41)$ & 2.72 \\
\hline Aweke & 2019 & $\rightarrow$ & $28.40(23.89,32.91)$ & 2.72 \\
\hline Masresha & 2012 & $\rightarrow$ & $37.20(33.28,41.12)$ & 2.77 \\
\hline Misgan & 2016 & $\rightarrow-$ & $32.20(27.50,36.90)$ & 2.70 \\
\hline Amare T1. & 2016 & - & $46.00(42.28,49.72)$ & 2.78 \\
\hline Dilano & 2018 & $\rightarrow$ & $32.80(28.88,36.72)$ & 2.77 \\
\hline Kalkidan H. & 2017 & $\leftarrow$ & $24.09(20.56,27.62)$ & 2.79 \\
\hline Araya & 2018 & $\rightarrow$ & $36.10(32.38,39.82)$ & 2.78 \\
\hline Selamawit & 2018 & $*$ & $49.40(46.66,52.14)$ & 2.84 \\
\hline Wagaye & 2016 & $\rightarrow$ & $57.70(53.78,61.62)$ & 2.77 \\
\hline Amare D. & 2010 & 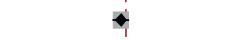 & $40.40(38.44,42.36)$ & 2.88 \\
\hline Abdibari & 2016 & $\rightarrow$ & $33.40(29.87,36.93)$ & 2.79 \\
\hline Birara & 2014 & $\leftarrow$ & $47.30(43.97,50.63)$ & 2.81 \\
\hline Atanaw & 2019 & $\rightarrow$ & $42.30(38.38,46.22)$ & 2.77 \\
\hline Yirgu F & 2015 & $\rightarrow-$ & $22.90(17.22,28.58)$ & 2.61 \\
\hline Ahmed & 2016 & 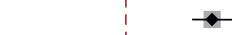 & $61.10(56.59,65.61)$ & 2.72 \\
\hline Hiwot Y. & 2015 & $\leftarrow$ & $45.80(42.27,45.80)$ & 2.79 \\
\hline Dish A. & 2013 & 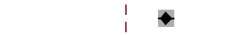 & $50.70(48.94,52.46)$ & 2.89 \\
\hline Seifu & 2017 & 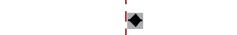 & $43.70(42.13,45.27)$ & 2.89 \\
\hline Demewoz & 2016 & $\bullet$ & $36.60(35.62,37.58)$ & 2.91 \\
\hline Kasahun T. & 2019 & - & $36.37(35.39,37.35)$ & 2.91 \\
\hline Abel G. & 2019 & $\leftarrow$ & $43.10(39.77,46.43)$ & 2.81 \\
\hline Tesfay & 2019 & $\rightarrow$ & $49.20(44.30,54.10)$ & 2.69 \\
\hline Jalane & 2019 & $1+$ & $44.40(40.48,48.32)$ & 2.77 \\
\hline Hiwot D. & 2017 & $\rightarrow$ & $39.30(35.97,42.63)$ & 2.81 \\
\hline Behailu T1. & 2014 & $\rightarrow$ & $60.60(56.68,64.52)$ & 2.77 \\
\hline Behailu T2 & 2014 & $\rightarrow$ & $39.00(34.10,43.90)$ & 2.69 \\
\hline EDHS & 2019 & -1 & $37.00(35.63,38.37)$ & 2.90 \\
\hline Overall $\left(I^{2}=9\right.$ & $p<0.001, Q=1461.93)$ & $\diamond$ & $41.50(38.65,44.34)$ & 100.00 \\
\hline \multicolumn{2}{|c|}{ Note: weights are from random effect analysis } & & & \\
\hline & & & & \\
\hline
\end{tabular}

Figure 2: The prevalence of stunting among children under five years of age and its 95\% CI in Ethiopia, 2010-2019.

that quality of studies did not significantly affect the pooled random prevalence of stunting (Supplementary Figure 1).

5.8. Cumulative Meta-Analysis. The cumulative meta-analyses indicated a stabilized trend of stunting prevalence among under-five children in the last 10 years, 2010 to 2019. The prevalence of stunting in 2010 and 2012 was lower than studies reported more recently from 2016 to 2019. Although the difference was irrelevant, there were upward and downward trends of stunting in the last 10 years. The prevalence of stunting was downward for the period 2010-2012, 2014-2015, and 2015-2016. However, the trend of stunting from late 2016 to 2019 was standing at $41 \%$ and $42 \%$ in down and up trends, with a slight difference in each year. For all years, a significant upward trend of stunting occurred in the period from 2012 to 2014 (Figure 3).

5.9. Publication Bias. The publication biases in this metaanalysis were examined using the subjective method, using funnel plot by visual checking for asymmetry, and objectively using Egger's test and Begg's test. In the funnel plot, all studies were distributed symmetrically. Both small- and large-scale studies were distributed on the bottom and top of the graph, assuring the absence of publication bias (Supplementary Figure 2).

The visual inspection of Begg's funnel plot did not identify substantial asymmetry, as nearly all of the studies laid within the 95\% CI. Both Egger's and Begg's objective tests also confirmed the absence of publication bias. According to Egger's test, the estimated bias coefficient (intercept) was 2.4, with a standard error of 2.07 and a $p$ value of 0.26 . Thus, the test provided evidence for the absence of small study effects. Similarly, the $p$ value for Begg's test was 0.87 that assured the absence of statistical evidence for publication bias.

5.10. Wealth Index and Stunting in Ethiopia. Sixteen studies were included to estimate the associations between the wealth index and stunting. The AOR of stunting varied from 0.83 [76] to 2.46 [70] from medium wealth index households and from 0.83 [76] to 6.05 [70] from low/poor wealth index households as the primary studies indicated. The AOR assured that the wealth index of households was associated with the prevalence of stunting in under-five children in 
Ethiopia from studies conducted between 20 January 2010 and 15 November 2019 [80, 82, 86]. In this meta-analysis, the odds of stunting increased at medium wealth index households compared to high/rich wealth index households (AOR 1.33, 95\% CI: 1.07, 1.65) (Figure 4). Similarly, the odds of stunting at low/poor wealth index households were greater compared with high/rich wealth index households, which was associated with stunting (AOR 1.92, 95\% CI: 1.46, 2.54) (Figure 5). The heterogeneity of pooled random effect size estimates among the 17 AOR reports using 16 studies on stunting and associations with low/poor or medium wealth index households was substantial $\left(I^{2}=63.8 \%\right.$ and $78.3 \%$ and $p<0.001$ for both low/poor and medium wealth index households, respectively) [52]. In addition to Cochran's Qtest and $I^{2}$ statistic, both the forest plot and Galbraith plot were considered to deal with this substantial degree of heterogeneity for both low/poor and medium wealth index households against the high/rich wealth index households. The Galbraith plot showed three studies that were out of the 95\% CI, and the CIs were not overlapping on the forest plot (Figure 4).

Similarly, in the low/poor wealth index households, the Galbraith plot showed five points were out of the 95\% CI, and the CIs were not overlapping on the forest plot (Figure 5).

5.11. Heterogeneity Deal. The pooled $I^{2}$ statistic from medium wealth index households and associations with stunting indicated a substantial degree of heterogeneity $\left(I^{2}=63.8 \%\right.$ ) [52] (Figure 4). The heterogeneity of the pooled random effect size estimates of low/poor wealth index households and associations with stunting had a discrepancy. The pooled $I^{2}$ statistic from low/poor wealth index households and associations with stunting indicated a considerable degree of heterogeneity $\left(I^{2}=78.3 \%\right)$ [52]. From the subgroup analysis of medium wealth index households and associations with stunting by design, the individual $I^{2}$ statistic ranged from $0 \%$ in the case-control design to $52.5 \%$ in the cross-sectional design, which have a low and moderate degree of heterogeneity, respectively (Figure 6).

The odds of stunting at medium wealth index households relative to high/rich wealth index households in casecontrol studies were AOR 1.67 (95\% CI: 1.41, 1.98) and in cross-sectional studies were AOR 1.19 (95\% CI: 0.94, 1.52) (Figure 6). Thus, the subgroup analysis by design in determining the associations between medium wealth index and stunting reported that cross-sectional studies were the more relevant heterogeneity moderators $\left(I^{2}=52.5\right.$ and $p=0.01)$, but the case-control studies were homogeneous $\left(I^{2}=0 \%\right.$ and $\left.p=0.37\right)$. Similarly, there was no statistical associations of stunting and medium wealth index in crosssectional studies (OR 1.19, 95\% CI: 0.94, 1.52), but there was an association between stunting and medium wealth index in case-control studies (OR 1.67, 95\% CI: 1.41, 1.98) (Figure 6). The pooled random effect size estimates of medium wealth index and associations with stunting by region had no associations in the two regions. However, in the Oromia region, a significant association was reported. The odds of stunting from medium wealth index households in comparison with high/rich wealth index households were AOR 2.05 (95\% CI: $1.17,3.58)$ and $I^{2}=0 \%$, although the regions considered in the subgroup analysis of medium wealth index and association with stunting were only SNNP, Amhara, and Oromia. The other regions have only a single study and a single AOR was reported in the subgroup analysis of medium wealth index and associations with stunting by region (Figure 7). The pooled random effect size estimates of low/ poor wealth index and associations with stunting by region had no association in the SNNP region, but in both Amhara and Oromia regions, a significant associations were reported with a pooled estimate (AOR $1.66(95 \% \mathrm{CI}: 1.18,2.34)$ in the Amhara region and AOR 4.04 (95\% CI: 2.29, 7.11) in the Oromia region) (Figure 8). In the subgroup analysis of low/ poor wealth index and associations with stunting by design, the individual $I^{2}$ statistics ranged from $73.3 \%$ in the casecontrol design to $77.9 \%$ in the cross-sectional design, which had a substantial degree of heterogeneity (Figure 9). The odds of stunting from low/poor wealth index households relative to high/rich wealth index households were AOR 2.69, (95\% CI: 1.71, 4.23) in case-control studies and AOR 1.69 (95\% CI: 1.20, 2.38) in cross-sectional studies (Figure 9). Thus, the subgroup analysis of low/poor wealth index and associations with stunting by design reported that both cross-sectional and case-control studies were relevant heterogeneity moderators $\left(I^{2}=77.9 \%\right.$ and $73.3 \%$ and $p=0.01$ for both, respectively). Both the case-control and crosssectional studies had statistically considerable associations with stunting and low/poor wealth index (Figure 9).

5.12. Publication Bias. This review assessed the risk of publication bias using funnel plots for symmetry by visual inspection for both the medium and poor household wealth index and associations with stunting. The plot appeared symmetrical and found no publication bias, with most studies concentrated on the top of the plot. The visual inspection of Begg's funnel plot also did not identify substantial asymmetry. Egger's linear regression test revealed evidence of no publication bias $(p=0.68)$, and Begg's rank correlation test again assured the absence of publication bias $(p=0.09)$.

\section{Discussion}

In this meta-analysis, the pooled prevalence of stunting in Ethiopia was 41.5\% (95\% CI: 38.65, 44.34). The 2018 united nation UNICEF, WHO, and World Bank joint report indicated that the prevalence of stunting was $22.2 \%$ in the world, 9.6\% in Latin American and Caribbean countries, $35 \%$ in south Asia, and 33.9\% in Sub-Saharan Africa [93]. This report confirmed that prevalence of stunting in Ethiopia was higher compared to the world, Latin American and Caribbean countries, south Asia, and Sub-Saharan Africa.

The consistently high prevalence of stunting in Ethiopia after 2010 might be due to the drought that occurred from 2010 to 2014 and the political instability that occurred after 2016. Both the drought and the political instability caused 


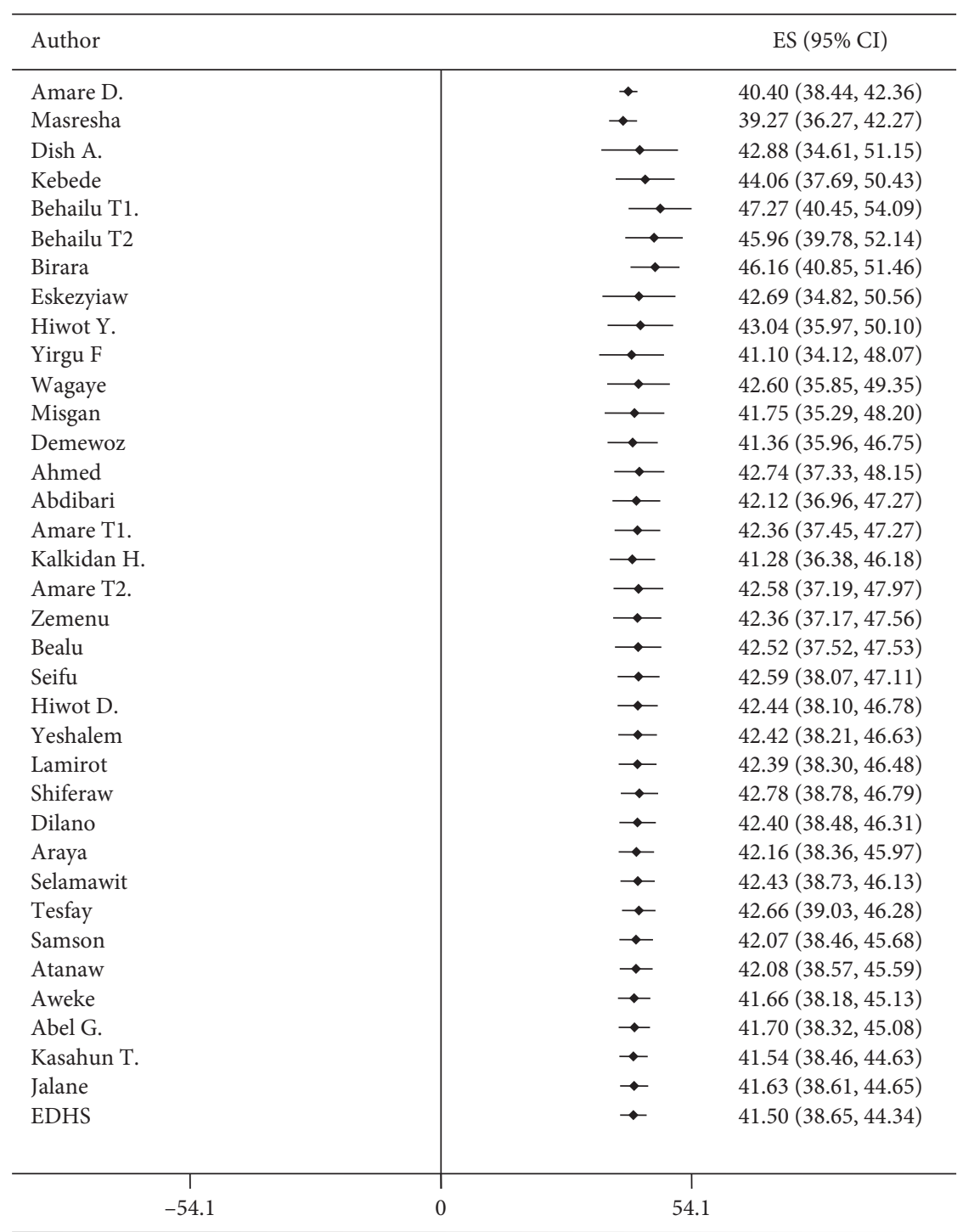

FIgURE 3: Trends of stunting from 2010 to 2019 using cumulative meta-analysis in Ethiopia.

immigration, which may have affected children disproportionately. The prevalence of stunting in our review was greater than another study that reported stunting as $22 \%$ globally, $24 \%$ in developing countries, and $6 \%$ in developed countries [94]. This indicates that stunting in Ethiopia was uniquely high and did not have significant improvements. The UNICEF, WHO, and World Bank joint estimation reported that the international trend in the prevalence of stunting decreased from $39.6 \%$ to $23.8 \%$ between 1990 and 2014 [95]. However, the prevalence of stunting in Ethiopia is still unchanged from the previous review [1]. The current review showed a decrease of only $0.5 \%$ from the previous review, which considers papers from 1997 to 2015, and revealed a $42 \%$ prevalence of stunting [1]. This consistently high prevalence of stunting forced us to hypothesizing that achieving the global targets of reducing stunting among children younger than 5 years by $40 \%$ in 2030 would be impossible for Ethiopia [96]. This hypothesis agreed with the fourth Ethiopian Health Sector Development Plan. The plan aimed to reduce undernutrition among under-five children by $30 \%$ in 2015, but it failed [97]. Beyond this, the current stunting reduction rate in Ethiopia is $2.8 \%$, which is far lower than the expected annual reduction rate of $6 \%$ to achieve the WHO's targets of stunting reduction [96]. Therefore, Ethiopia will not reach the United Nations sustainable developmental goals of ending child malnutrition by 2030 or the national commitment to the Seqota Declaration [98] at the current rate of reduction and type of programmes being implemented. On the other hand, this review agreed with the report of the WHO, UNICEF, and World Bank that indicated the number of stunted children in Africa is expected to increase from 56 million in 2010 to 61 million by the year 2025 [99]. The match might be because of analogous geographic location, data, and methodological quality both in the current review and the joint report. Unlike the previous review [1], in this meta-analysis, the prevalence of stunting did not have one directional track, yet the peak prevalence of stunting appeared in the year 2014, with the years 2013-2015 


\begin{tabular}{|c|c|c|}
\hline $\begin{array}{l}\text { Author } \\
\text { Year }\end{array}$ & ES $(95 \%$ CI $)$ & $\begin{array}{c}\text { Weight } \\
(\%)\end{array}$ \\
\hline Kidanemaryam (2019) & $2.46(1.37,4.43)$ & 6.64 \\
\hline Amare D. (2010) & $0.82(0.67,1.00)$ & 11.80 \\
\hline Behailu T1 (2014) & $0.90(0.23,3.57)$ & 2.09 \\
\hline Behailu T2 (2014) & $0.82(0.31,2.18)$ & 3.55 \\
\hline Kebede (2013) & $2.23(1.24,4.01)$ & 6.64 \\
\hline Birara (2014) & $1.00(0.68,1.48)$ & 9.14 \\
\hline Amare T. (2017) & $1.49(1.01,2.21)$ & 9.14 \\
\hline Zufan (2019) & $1.65(1.36,2.01)$ & 11.80 \\
\hline Terefe (2017) & $1.49(1.01,2.21)$ & 9.14 \\
\hline Samson (2019) & $2.46(0.62,9.70)$ & 2.09 \\
\hline Atanaw (2019) & $1.11(0.75,1.64)$ & 9.14 \\
\hline Taye (2018) & $1.82(0.01,297.65)$ & 0.18 \\
\hline Kalkidan (2017) & $0.82(0.12,5.81)$ & 1.11 \\
\hline Yirgu (2015) & $1.22(0.00,3102.17)$ & 0.08 \\
\hline Seifu (2017) & $0.90(0.34,2.39)$ & 3.55 \\
\hline Wagaye (2016) & $0.90(0.41,1.98)$ & 4.81 \\
\hline Dilano (2018) & $1.82(1.23,2.70)$ & 9.14 \\
\hline Overall $\left(I^{2}=63.8 \%, p<0.001, Q=44.21\right)$ & $1.33(1.07,1.65)$ & 100.00 \\
\hline Note: weights are from random effect analysis & & \\
\hline 0.1 & & \\
\hline
\end{tabular}

FIgURE 4: Association of medium household wealth index with stunting among children under five years of age and its 95\% CI in Ethiopia, 2010-2019.

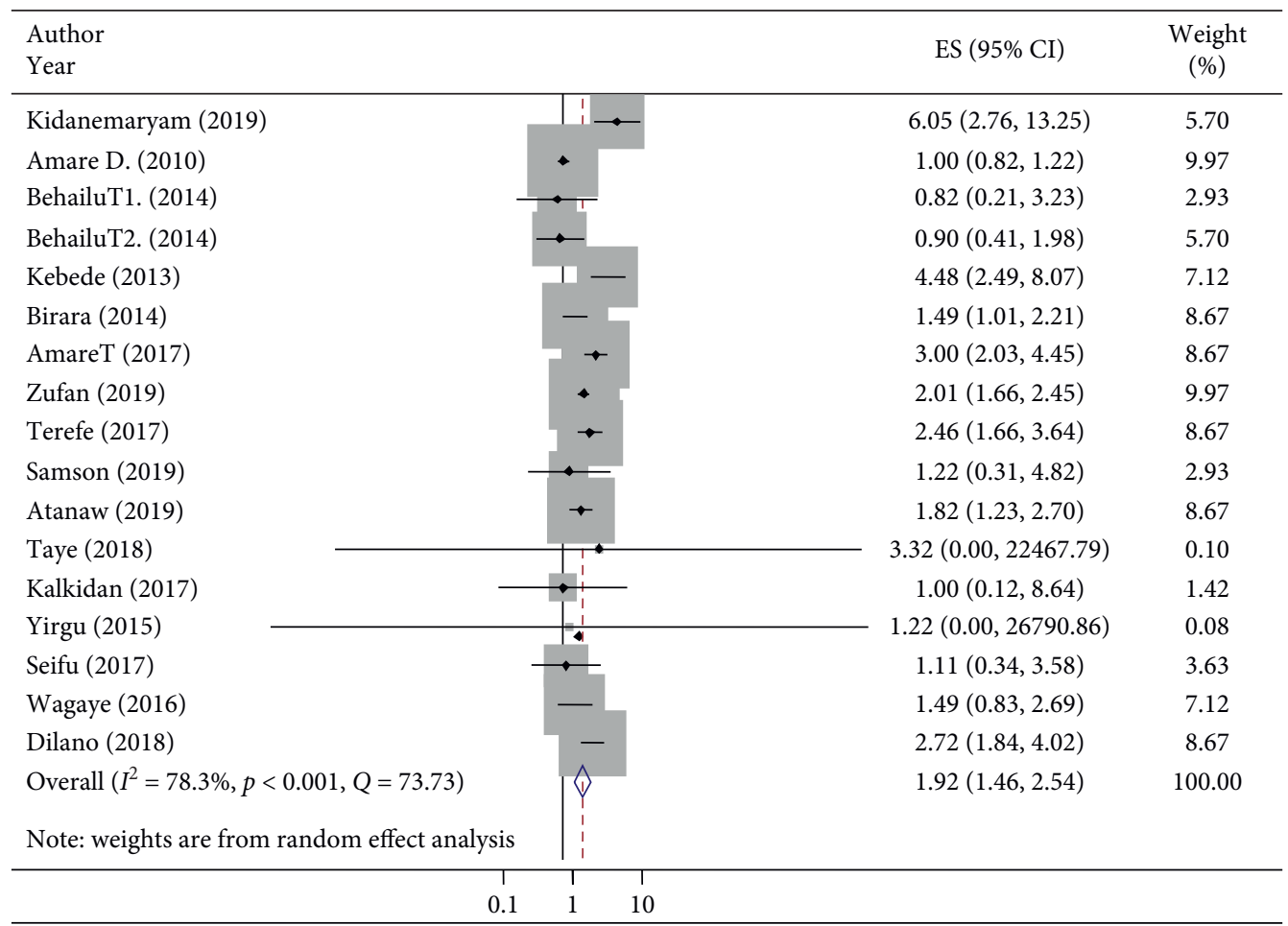

FIGURE 5: The pooled associations of stunting and poor household wealth index in Ethiopia. 


\begin{tabular}{|c|c|c|c|c|}
\hline Author & Year & & ES $(95 \%$ CI $)$ & Weight (\%) \\
\hline \multicolumn{5}{|l|}{ Case-control } \\
\hline Kidanemaryam & 2019 & $\rightarrow$ & $2.46(1.37,4.43)$ & 6.64 \\
\hline Zufan & 2019 & $\bullet$ & $1.65(1.36,2.01)$ & 11.80 \\
\hline Terefe & 2017 & & $1.49(1.01,2.21)$ & 9.14 \\
\hline \multicolumn{2}{|c|}{ Subtotal $\left(I^{2}=0.0 \%, p=0.37, Q=2.00\right)$} & & $1.67(1.41,1.98)$ & 27.58 \\
\hline \multicolumn{5}{|l|}{ Cros-sectional } \\
\hline Amare D. & 2010 & • & $0.82(0.67,1.00)$ & 11.80 \\
\hline Behailu T1 & 2014 & & $0.90(0.23,3.57)$ & 2.09 \\
\hline Behailu T2 & 2014 & & $0.82(0.31,2.18)$ & 3.55 \\
\hline Kebede & 2013 & $\rightarrow$ & $2.23(1.24,4.01)$ & 6.64 \\
\hline Birara & 2014 & $\rightarrow$ & $1.00(0.68,1.48)$ & 9.14 \\
\hline AmareT. & 2017 & $\rightarrow$ & $1.49(1.01,2.21)$ & 9.14 \\
\hline Samson & 2019 & & $2.46(0.62,9.70)$ & 2.09 \\
\hline Atanaw & 2019 & $\rightarrow$ & $1.11(0.75,1.64)$ & 9.14 \\
\hline Kalkidan & 2017 & & $0.82(0.12,5.81)$ & 1.11 \\
\hline Yirgu & 2015 & 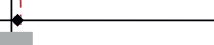 & $1.22(0.00,3102.17)$ & 0.08 \\
\hline Seifu & 2017 & & $0.90(0.34,2.39)$ & 3.55 \\
\hline Wagaye & 2016 & & $0.90(0.41,1.98)$ & 4.81 \\
\hline Dilano & 2018 & $\rightarrow$ & $1.82(1.23,2.70)$ & 9.14 \\
\hline \multicolumn{2}{|c|}{ Subtotal $\left(I^{2}=52.5 \%, p<0.05, Q=25.24\right)$} & & $1.19(0.94,1.52)$ & 72.25 \\
\hline \multicolumn{5}{|l|}{ Cohort } \\
\hline \multirow[t]{2}{*}{ Taye } & 2018 & - & $1.82(0.01,297.65)$ & 0.18 \\
\hline & & $=$ & $1.82(0.01,297.65)$ & 0.18 \\
\hline \multicolumn{2}{|c|}{ Overall $\left(I^{2}=63.8 \%, p<0.001, Q=44.21\right)$} & 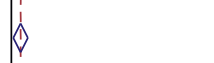 & $1.33(1.07,1.65)$ & 100.00 \\
\hline \multicolumn{5}{|c|}{ Note: weights are from random effect analysis } \\
\hline & 1 & T & & \\
\hline & 0.1 & 10 & & \\
\hline
\end{tabular}

FIGURE 6: Subgroup analysis (by design) on the association of medium wealth index with stunting and its 95\% CI in Ethiopia, 2010-2019.

having the highest relative prevalence of stunting of all years. The prevalence of stunting in the years 2016-2019 was higher than the prevalence in the years 2010-2012. This makes stunting a tragic puzzle for Ethiopia, because the years 2015-2019 had relatively good economic improvements, despite the political instability across the country in the years 2016-2019.

In considering this review and meta-analysis, the authors recommend a qualitative research, mainly a focused ethnographic study to explore the culture of both rural and urban villages on caring and handling children, preparing the meals of children, health-seeking behaviour of mothers during illness, and perception of the community towards nutrition from preconception to the end of adolescence. The stunting scenario in Ethiopia contradicts with the literature that children throughout the world can attain full growth potential if they are nurtured in healthy environments and their caregivers strictly stick to the recommended health, nutrition, and health care practices [100]. However, in Ethiopia, the prevalence of stunting was not decreased, while both the economic status of the community and the health care services provided were improved. Although the economic changes brought to Ethiopia were not paramount in decreasing stunting as per the WHO 2030 plan [11] and HSTP 2015 [97], a relative reduction must occur. We are also considering the drought from 2010 to 2014 and immigration from 2016 to 2019 (Ref), which might reverse the trends of reduction in stunting. This immigration and drought effect on stunting may become doubled because of the current COVID-19 pandemic in the next years. World Health Organization is warning that COVID-19 may push millions of people into poverty and malnourishment. This is also true in Ethiopia as a number of reports indicated.

Nonetheless, the prevalence of stunting from late 2010 to 2019 should not be $41.5 \%$. Because, unlike most of the SubSaharan Africa countries, Ethiopia had the highest and continuous reduction in the prevalence of stunting between 2000 and 2011, where stunting decreased from $57.7 \%$ in 2000 to $50.8 \%$ in 2005 to $44.3 \%$ in 2011 [101]. With regard to the sensitivity analysis of this review, a $43.19 \%$ (95\% CI: 42.62, 43.76) prevalence of stunting was computed, while 10 papers with low scores were removed. However, the sensitivity analysis from the previous review reported a $40 \%$ (95\% CI; $32,48)$ prevalence of stunting [1]. Thus, the current review has a higher prevalence of stunting (by 3.19\%.) The reason for such a difference in prevalence might be the studies included in our review reported a higher prevalence of stunting, particularly studies conducted from late 2016 to 2019. However, the important question is why stunting became higher than the previous review. Although the interval prevalence of the previous review and the current review is similar, there was a figurative difference. The reason 


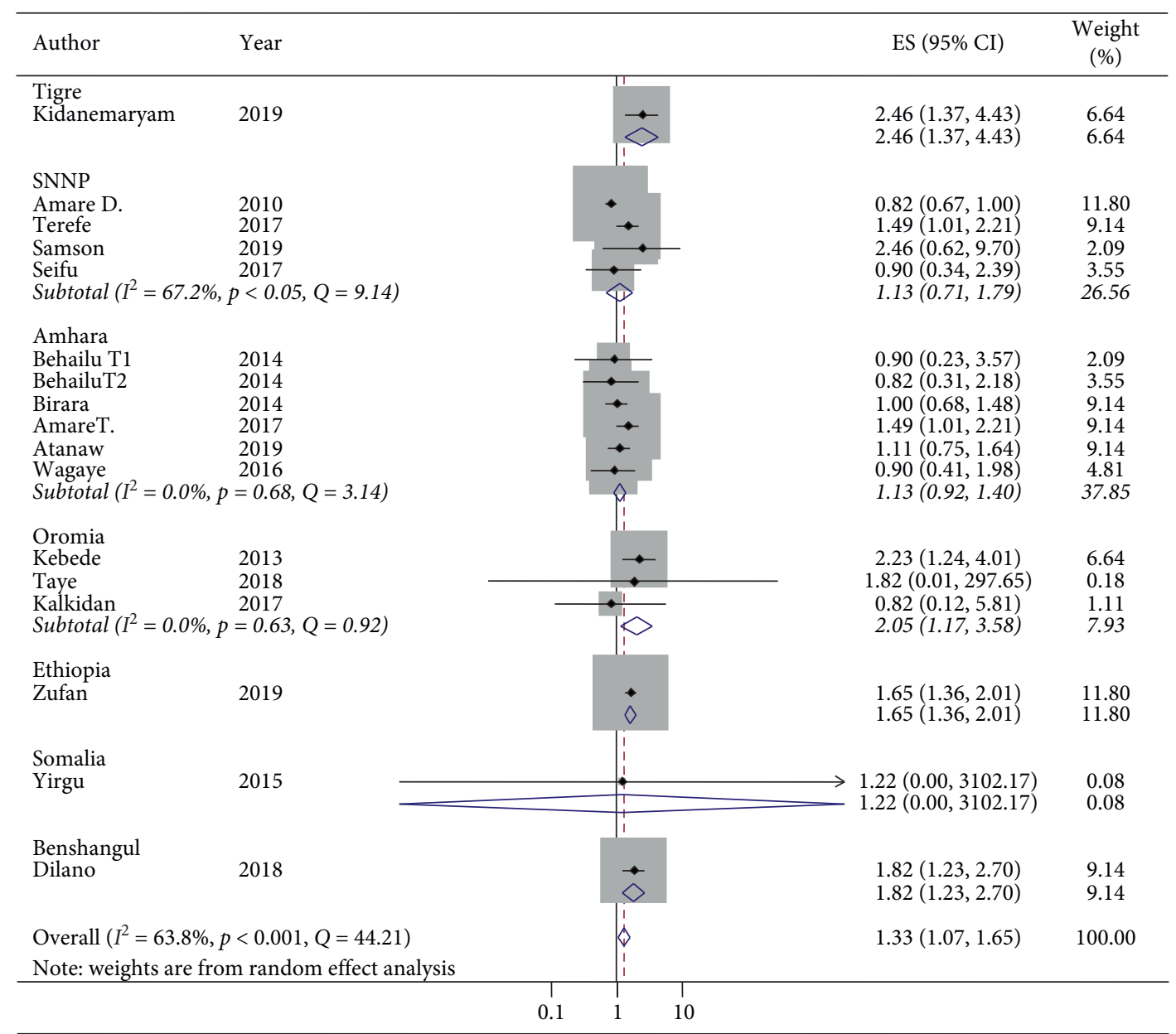

FIgURE 7: Subgroup analysis (by region) on the association of medium wealth index with stunting and its 95\% CI in Ethiopia, 2010-2019.

might be because of the researchers concern to address the most vulnerable communities that may have not been addressed before the year 2010 and could not consider in the previous review. On the contrary, those papers might have a high prevalence of stunting and were included in our review.

The other causes for such a high prevalence of stunting in these years might be the drought in Ethiopia from 2010 to 2014 caused by La Niña $[102,103]$. Currently, the number of people targeted for relief food and cash support remains largely unchanged due to the significant spike in internal displacement since April 2018 [104]. The pooled prevalence of stunting by subgroup analysis showed marked differences with regard to the prevalence of stunting among regions. According to the WHO's 2010 classification, the prevalence of stunting was considered "very high" (above 40) in the Amhara region, Ethiopia, Oromia region, Ethiopia, Tigray region, Ethiopia, and country-based studies, Ethiopia; "high" (30-39\%) in the SNNP region, Ethiopia, and Afar Region, Ethiopia; and "medium" (20-29\%) in Somalia Region, Ethiopia. Of the studies included in this review, there was no region that had a prevalence of stunting that was considered "low" (<20\%) [44]. The high prevalence of stunting in the Amhara and Oromia regions might be as a result of many numbers of children at the household level and have the largest population in the country (EDHS, 2016), which might contribute to household food insecurity. The 2016 EDHS report [45] revealed that the prevalence of stunting was $46 \%$ in the Amhara region, $43 \%$ in the Benishangul-Gumuz region, $41 \%$ in the Afar region, $39 \%$ in the Tigray region, $39 \%$ in the SNNP region, $27 \%$ in the Somalia region, and $37 \%$ in the Oromia region. The subgroup meta-analysis reported that the prevalence of stunting was $48.21 \%$ in the Amhara region, $37.78 \%$ in the Afar region, $42.55 \%$ in the Tigray region, $36.45 \%$ in the SNNP region, $43.53 \%$ in the Oromia region, and $28.4 \%$ in the Somalia region. The 2016 EDHS report and this subgroup metaanalysis have results that agree in some regions and some results that are contradicted in other regions. For example, the subgroup analysis of this review and the 2016 EDHS report have close prevalence in the Amhara, SNNP, and Somalia regions. Regarding the associations between stunting and the wealth index, this review and meta-analysis identifies that low wealth quintiles are associated with stunting. This meta-analysis indicated that the pooled odds of stunting due to having a low/poor wealth index were 1.92 (95\% CI: 1.46, 2.54) and due to having a medium wealth index was 1.33 (95\% CI: 1.07, 1.65) compared to households that had a high/rich wealth index. This association of 


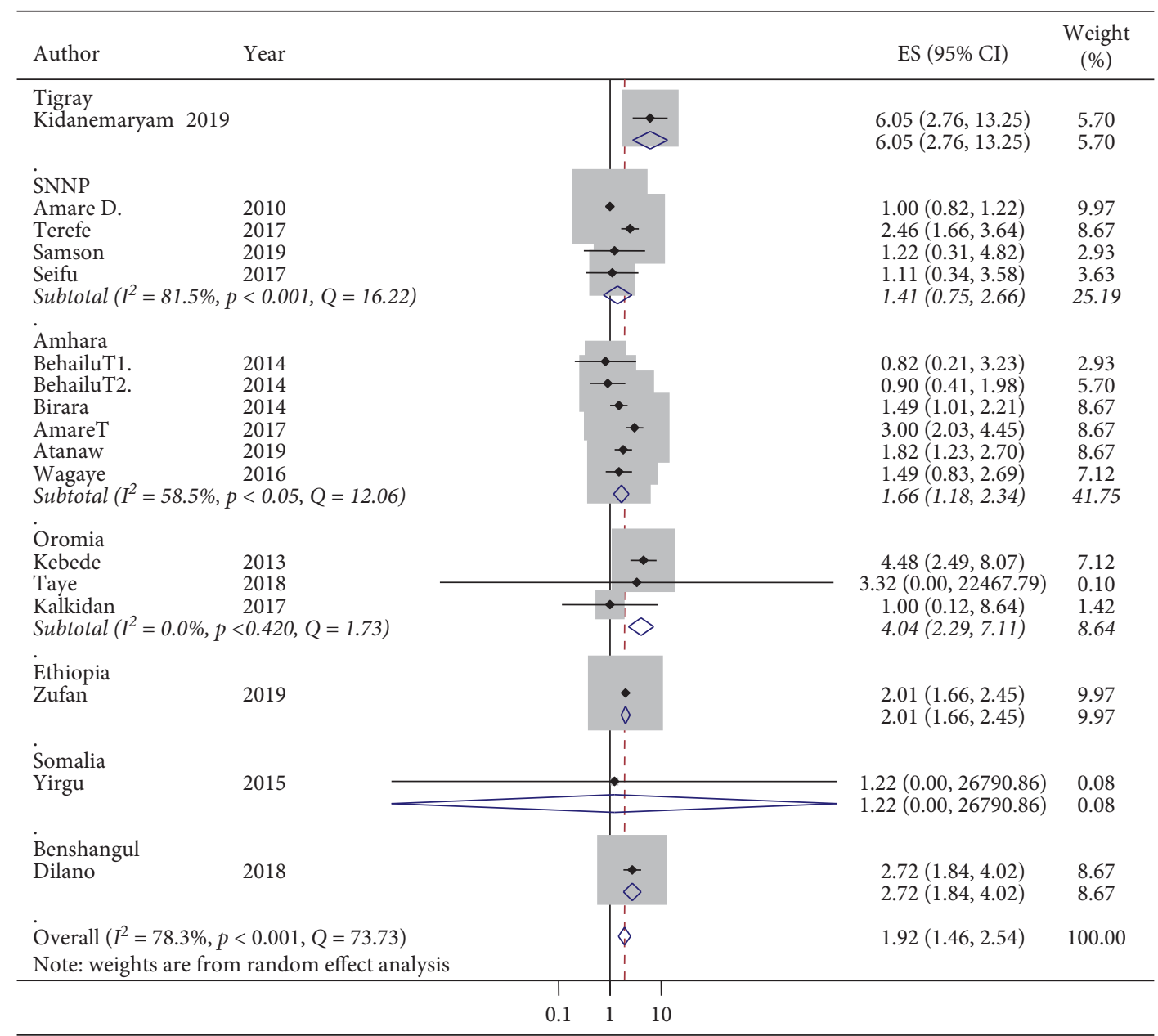

Figure 8: Subgroup analysis (by region) on the association of poor household wealth index and stunting and its 95\% CI in Ethiopia, 2010-2019.

stunting and the wealth index was supported by a report that stunting is greatly influenced by three important factors: food, health, and quality of care provided for children [45].

In relation to this, other evidence has reported that combating stunting among children depends on accessing diversified and nutrient-rich foods, providing appropriate care for mothers and children, creating appropriate health care services and a healthy environment, including safe water, good hygiene, and sanitation [105]. Food, health, and health care services are affected by social, economic, and political factors. To afford the above important conditions, the socioeconomic status of a given household is an invaluable condition [106]. Although the determinant factors of stunting are diverse, socioeconomic status plays a great role in the occurrence of stunting. When socioeconomic status improves and poverty is reduced, child stunting will be improved by getting greater access to food, improved maternal and child care, and better public health care services $[54,107,108]$. This meta-analysis agreed with the study done by Krishna et al. that was conducted in four low- and middle-income countries (Ethiopia, India, Peru, and Vietnam) [109]. A further analysis of the demographic and health surveys of Rwanda (2014-2015) and Uganda (1995,
2001, 2006, and 2011) showed the same result [110] to this review. The association between stunting and wealth index was also reported by other studies conducted from south Asia (Afghanistan, Bangladesh, India, Nepal, and Pakistan) $[111,112]$. Thus, socioeconomic status greatly influences the living standard, which is explained by the wealth index and in turn caused stunting. This implies that improving the living standard of the community will decrease the occurrence of stunting. The finding of this review contradicts the previous meta-analysis [56], where the wealth index was not a factor for stunting.

This disagreement might be because of differences in the sample size, search date, and number of studies included. In addition, the review by Kalkidan had considerable heterogeneity $\left(I^{2}=92 \%\right)$, but the heterogeneity in our review was lower $\left(I^{2}=63.8 \%\right)$. Thus, the lower degree of heterogeneity in our review might indicate the robustness of its scientific quality. In contrast to the previous review, we performed subgroup analyses by region and by study design. The subgroup analysis by design indicated that cross-sectional studies had moderate heterogeneity $\left(I^{2}=52.5 \%\right)$, but the case-control studies were homogeneous $\left(I^{2}=0 \%\right)$. This means that the review might be more relevant than the 


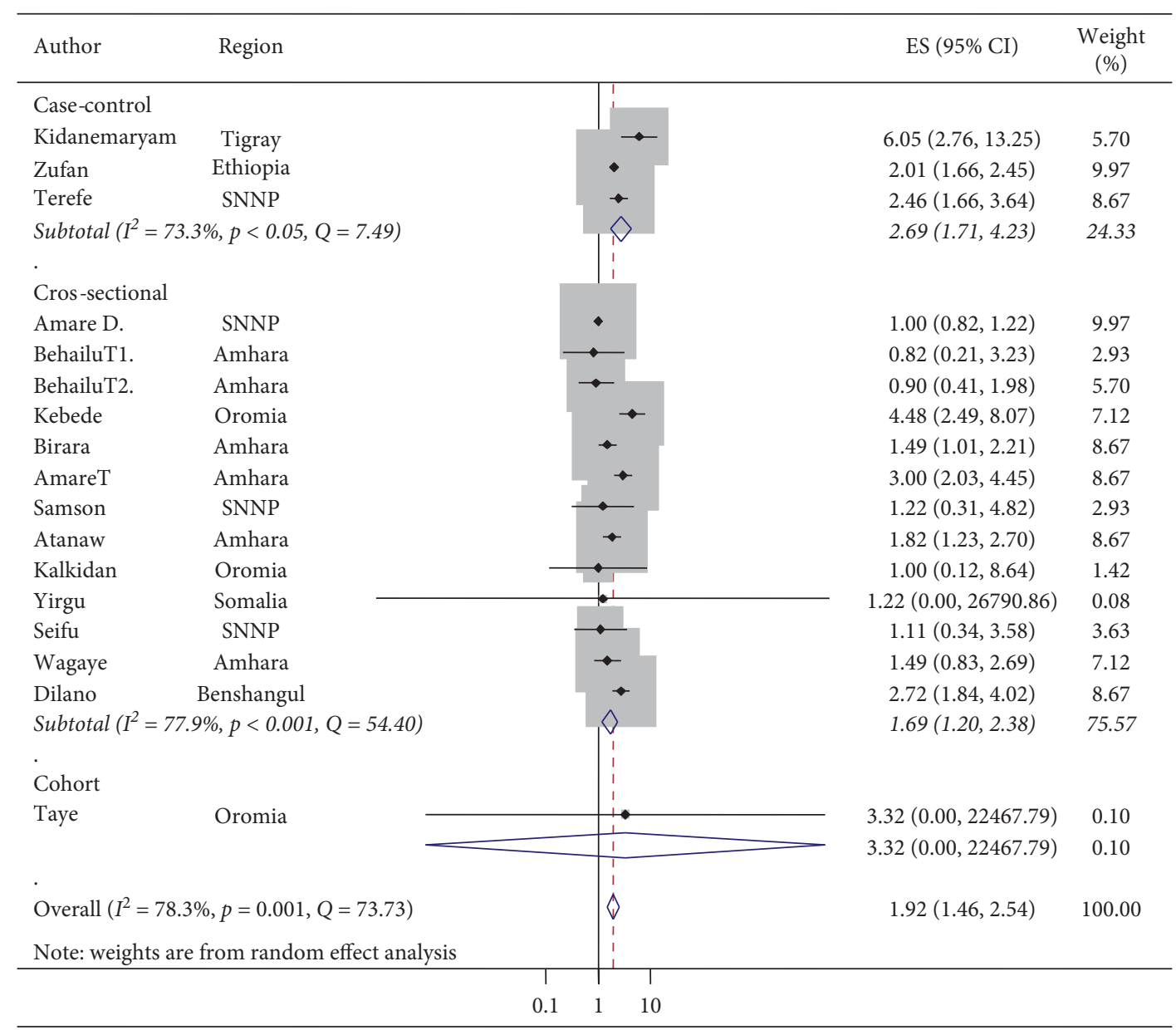

Figure 9: Subgroup analysis (by design) on the association of poor household wealth index and stunting and its 95\% CI in Ethiopia, 2010-2019.

previous one because of its homogeneity. Additionally, the review by Kalkidan Hassen categorized the wealth index into two quintiles: low and high. However, we classified the wealth index into three quintiles: low/poor, medium, and high/rich. This might be the other reason for the contradictory pooled estimation. In contrary to the review by Kalkidan and Tefera, our review agreed with the study done by Fenske et al., where the wealth index had the largest effect on stunting [113]. The similarity might be that wealth is a universal factor for stunting irrespective of cultural, educational, and sociodemographic data, because children from low/poor wealth index households are less likely to have adequate food. This review agreed with a review that was conducted in urban setting, and reported low household income was identified as a risk factor for stunting $[114,115]$. This similarity might support that the wealth index is a known underlying cause of stunting. Particularly, in urban settings, the dependence on cash flow might emphasize that household income is a real cause of stunting. The findings of the current review agree with the reports of Headey and Biadgilign who reported that the wealth index and stunting have an association $[116,117]$. The similarity might be due to the fact that the study populations are similar. Both of the studies were nation-based studies on under-five children.
This review agreed with a study that reported the presence of an association between stunting and wealth index, with a substantial wealth gap in stunting, even after controlling for wealth-related differences [118]. This study indicated that Ethiopian children in the top $60 \%$ of the wealth distribution are 3.9 percentage points less likely to be stunted compared with an equivalent child that is among the poorest $40 \%$ [118]. The review agreed with a nation-based study conducted in Ghana that showed the wealth index was significantly associated with stunting. The study showed that children residing in the lowest wealth quintile households had significantly increased probabilities of being stunted in comparison to children residing in the highest wealth quintile households (AOR 2.36, 95\% CI: 1.29, 4.30) [119].

From this literature and our review, we recognize a reduction of stunting by $40 \%$ as per the WHO's 2030 plan might be achieved through improving the economic status of the community in collaboration with the agriculture sectors. Some authors have agreed and recommended that strengthening the existing micronutrient interventions and community-based management of severe acute malnutrition programmes [120] have public health importance in reducing the prevalence of stunting. This review is supported by another study that reported that a stunted child was more 
likely to have been born into a low-income household; hence, intergenerational transmission of poverty and of childhood stunting is a possibility and may become a vicious cycle [121]. This again agreed with a nation-based study in Ethiopia that reported under the recent Situational Analysis of the Nutrition Sector (SITAN), which indicated an association between poverty and stunting. The nation-based study indicated that children from lowest wealth quintile were found to be stunted [122].

This review agreed with the previous studies that reported children born to severely and moderately food insecure households were more likely to be stunted than children born to food-secure households [61, 123]. This review agreed with a study that stunting disproportionately affects children in poorer countries and from poorer households [99, 108]. The review also agreed with studies that reported poorer households experience a higher prevalence of anthropometric failure [124-128].

\section{Conclusion}

Despite the great deal of heterogeneity, the present review revealed significant findings on the pooled prevalence of stunting and its associations with wealth index, which could be used for monitoring the burden of stunting in Ethiopia. This review revealed that stunting is still stable and ominously high in the country. The burden of stunting is overriding in the Amhara region of the country, Ethiopia. Moreover, stunting is associated with the economic class in which children from low/poor economic class become stunted compared with high/rich economic classes. Thus, the implementation of policies to reverse stunting should get the concern of the government, the sector that leads Seqota Declaration, which planned to end stunting by 2020. In particular, the health and agriculture sectors need to act together to improve the socioeconomic status of the community. The intervention should consider the highly affected regions in prioritizing the intervention.

\section{Abbreviations}

\section{AOR: $\quad$ Adjusted odds ratio}

CI: $\quad$ Confidence interval

EDHS: Ethiopian Demography and Health Survey

UNICEF: United Nation International Children Fund

WHO: World Health Organization

WB: World Bank

SNNPR: South Nations, Nationalities, and Peoples' Region

PRISMA: Preferred Reporting Items for Systematic

Reviews and Meta-Analyses

GDP: Gross domestic product

ANC: Antenatal care

BMI: $\quad$ Body mass index

JBI: Joanna Briggs Institute.

\section{Data Availability}

The raw materials that support the conclusions of this systematic review are incorporated to the manuscript and presented in tables or figures in the result section and as the supplementary file.

\section{Additional Points}

Limitations. The limitation of this review was the high heterogeneity in the samples of the retrieved studies, which might be because of differences in the locations and populations of the studies. This also causes to have a pooled prevalence with high heterogeneity.

\section{Ethical Approval}

Since it is a systematic review and meta-analysis using primary studies published in journals or institutions blog, the authors did not request ethical approval from a concerned body.

\section{Consent}

Since it is a systematic review and meta-analysis using primary studies published in journals or institutions blog, the authors did not take consent from a concerned body.

\section{Disclosure}

The funder had no role in study design, data extraction and analysis, decision to publish, or preparation of the manuscript. The contents are the responsibility of the authors and do not necessarily reflect the views of funders.

\section{Conflicts of Interest}

The authors declare that they have no conflicts of interest.

\section{Authors' Contributions}

$\mathrm{AA}, \mathrm{AD}, \mathrm{NF}, \mathrm{MA}, \mathrm{TA}$, and MWK conceived the title and designed the review. MW, NF, TA, MA, AA, and AD developed the searching terms. TA, NF, MWK, AA, MA, and AD developed the data extraction sheet. AA, MA, NF, TA, $\mathrm{AD}$, and $\mathrm{MWK}$ critically revised the review. AA and $\mathrm{MW}$ analyzed the data. KWL, TA, MA, NF, AA, and AD wrote the final review. All the authors had read and approved the final version of this manuscript. The authors agreed to be accountable for all aspects of this work.

\section{Acknowledgments}

This research was conducted through the systematic review and meta-analysis training project to establish a regional knowledge hub under the facilitation of Amhara Public Health Institute. The authors wish to acknowledge the contribution and technical support of the following organizations which were instrumental in making the training more successful: USAID Transform: Primary Health Care, JSI Research and Training Institute Inc/L1ok Project, University of Gondar, Institute of Public Health, and Amhara Public Health Institute (APHI). The authors thank Dr. 
Gizachew Yismaw, Director of APHI, Dr. Mahteme Haile, Deputy Director of APHI, and Mr. Taye Zeru, Health Research Director of APHI for their brilliant leadership in conceptualizing the establishment of the regional knowledge hub through providing systematic and meta-analysis courses to the members for two years. The authors also thank all the collaborating partners in establishing the knowledge hub and implementing the systematic review and meta-analysis training course and the knowledge hub members who were part of these training sessions. This article was prepared as part of establishing a regional knowledge hub implemented by the Amhara Public Health Institute with the collaboration of USAID Transform: Primary Health Care. Regional knowledge hub established through providing systematic review and meta-analysis capacity building training. The training process was funded/supported by USAID Transform: Primary Health care, JSI/L10K Project, Amhara Public Health Institute.

\section{Supplementary Materials}

Supplementary Figure 1: sensitivity analysis of high-quality studies in assessing stunting among children under five years of age in Ethiopia and its 95\% CI in Ethiopia, 2010-2019. Supplementary Figure 2: funnel plot to assess publication bias in assessing stunting among children under five years of age in Ethiopia, 2010-2019. (Supplementary Materials)

\section{References}

[1] A. Abdulahi, S. Shab-Bidar, S. Rezaei, and K. Djafarian, "Nutritional status of under five children in Ethiopia: a systematic review and meta-analysis," Ethiopian Journal of Health Sciences, vol. 27, no. 2, pp. 175-188, 2017.

[2] K. H. Abate and T. Belachew, "Chronic malnutrition among under five children of Ethiopia may not be economic: a systematic review and meta-analysis," Ethiopian Journal of Health Sciences, vol. 29, no. 2, p. 265, 2019.

[3] A. Shiferaw, Productive Capacity and Economic Growth in Ethiopia, United Nations, Department of Economics and Social Affairs, New York, NY, USA, 2017.

[4] MoFED, The Federal Democratic Republic of Ethiopia Growth and Transformation Plan (GTP) 2010/11-2014/15, 2010.

[5] National Planning Commission, "The second growth and transformation plan (GTP II) (2015/16-2019/20) (draft)," The Federal Democratic Republic of Ethiopia, Addis Ababa, Ethiopia, 2015.

[6] K. F. Gebru, W. M. Haileselassie, A. H. Temesgen, A. O. Seid, and B. A. Mulugeta, "Determinants of stunting among under-five children in Ethiopia: a multilevel mixed-effects analysis of 2016 Ethiopian demographic and health survey data," BMC Pediatrics, vol. 19, no. 1, p. 176, 2019.

[7] EPHI, Ethiopia National Food Consumption Survey, Ethiopian Public Health Institute (EPHI), Addis Ababa, Ethiopia, 2013.

[8] O. A. Otekunrin, O. A. Otekunrin, B. Sawicka, and I. A. Ayinde, "Three decades of fighting against hunger in Africa: progress, challenges and opportunities," World $\mathrm{Nu}$ trition, vol. 11, no. 3, pp. 86-111, 2020.

[9] World Health Organization, WHA Global Nutrition Target 2025: Stunting Policy Brief, WHO, Geneva, Switzerland, 2010 .
[10] T. Y. R. You, M. F. Lyles, D. Gong, B. J. Nicklas, J. C. K. Wells et al., "WHA global nutrition target 2025: stunting policy brief," European Journal of Clinical Nutrition, vol. 92, 2010.

[11] IFP, RII: Global Nutrition Report in 2016 from Promise to Impact, Ending Malnutrition by 2030 Summary, 2016.

[12] H. Alderman, J. R. Behrman, and J. Hoddinott, Nutrition, Malnutrition, and Economic Growth. Health and Economic Growth: Findings and Policy Implications, pp. 169-194, 2005.

[13] T. Gödecke, A. J. Stein, and M. Qaim, "The global burden of chronic and hidden hunger: trends and determinants," Global Food Security, vol. 17, pp. 21-29, 2018.

[14] World Health Organization, Nutrition in the WHO African Region, WHO, Geneva, Switzerland, 2017.

[15] Nations FaAOotU, Regional Overview of Food Security and Nutrition, the Food Security and Nutrition-Conflict Nexus Building Resilience for Food Security, Nutrition and Peace Africa, 2017.

[16] Z. A. Bhutta, J. K. Das, A. Rizvi et al., "Evidence-based interventions for improvement of maternal and child nutrition: what can be done and at what cost?" The Lancet, vol. 382, no. 9890, pp. 452-477, 2013.

[17] UNICEF-WHO-The World Bank, Levels and Trends in Child Malnutrition, WHO, Geneva, Switzerland, 2016.

[18] UNICEF-WHO-The World Bank, The World Bank Joint Child Malnutrition, United Nations Child Fund, New York, NY, USA, 2013.

[19] EDHS, "Demographic and health survey 2016: key indicators report," The DHS Program ICF, vol. 363, p. 364, 2016.

[20] World Health Organization, Childhood Stunting: Context, Causes and Consequences, WHO, Geneva, Switzerland, 2013.

[21] E. Desalegn, K. Fikre, and T. Bosha, "Stunting and its associated factors in under five years old children: the case of Hawassa University Technology villages, Southern Ethiopia," Journal of Environmental Science, Toxicology and Food Technology, vol. 10, no. 11, pp. 25-31, 2016.

[22] S. A. S. Mantovani, A. A. Ramalho, T. M. Pereira et al., "Stunting in children under five years old is still a health problem in the Western Brazilian Amazon: a populationbased study in Assis Brasil, Acre, Brazil," Ciência \& Saúde Coletiva, vol. 21, no. 7, pp. 2257-2266, 2016.

[23] T. Y. Bogale, E. T. Bala, M. Tadesse, and B. O. Asamoah, "Prevalence and associated factors for stunting among 6-12 years old school age children from rural community of Humbo district, Southern Ethiopia," BMC Public Health, vol. 18, no. 1, p. 653, 2018.

[24] B. Batiro, T. Demissie, Y. Halala, and A. A. Anjulo, "Determinants of stunting among children aged 6-59 months at Kindo Didaye woreda, Wolaita Zone, Southern Ethiopia: unmatched case control study," PLoS One, vol. 12, no. 12, Article ID e0189106, 2017.

[25] Z. Y. Kassa, T. Behailu, A. Mekonnen, M. Teshome, and S. Yeshitila, "Malnutrition and associated factors among under five children (6-59 months) at Shashemene referral hospital, west Arsi zone, Oromia, Ethiopia," Current Pediatric Research, vol. 21, no. 1, 2017.

[26] S. B. Geberselassie, S. M. Abebe, Y. A. Melsew, S. M. Mutuku, and M. M. Wassie, "Prevalence of stunting and its associated factors among children 6-59 months of age in LiboKemekem district, Northwest Ethiopia; a community based cross sectional study," PLoS One, vol. 13, no. 5, Article ID e0195361, 2018.

[27] R. A. Guled, N. M. Mamat, W. A. M. A. Bakar, T. Belachew, and N. Assefa, "Undernutrition prevalence and its determinants among children below five years of age in Shabelle 
Zone, Somali region, Eastern Ethiopia," International Journal of Allied Health Sciences, vol. 1, no. 2, pp. 72-91, 2017.

[28] Z. Dewana, T. Fikadu, W. Facha, and N. Mekonnen, "Prevalence and predictors of stunting among children of age between 24 to 59 months in Butajira town and surrounding district, Gurage zone, Southern Ethiopia," Health Science Journals, vol. 11, no. 4, p. 518, 2017.

[29] E. C. B. Fernandes, T. G. d. Castro, and D. S. Sartorelli, "Associated factors of malnutrition among African children under five years old, Bom Jesus, Angola," Revista de Nutrição, vol. 30, no. 1, pp. 33-44, 2017.

[30] I. O. Senbanjo, K. A. Oshikoya, O. O. Odusanya, and O. F. Njokanma, "Prevalence of and risk factors for stunting among school children and adolescents in Abeokuta, Southwest Nigeria," Journal of Health, Population, and Nutrition, vol. 29, no. 4, p. 364, 2011.

[31] J. Tariq, A. Sajjad, R. Zakar, M. Zakar, and F. Fischer, "Factors associated with undernutrition in children under the age of two years: secondary data analysis based on the Pakistan demographic and health survey 2012-2013," Nutrients, vol. 10, no. 6, p. 676, 2018.

[32] M. Asfaw, M. Wondaferash, M. Taha, and L. Dube, "Prevalence of undernutrition and associated factors among children aged between six to fifty nine months in Bule Hora district, South Ethiopia," BMC Public Health, vol. 15, no. 1, p. 41, 2015.

[33] A. Haile and T. Amboma, "Children's nutritional status and its determinants in small towns, Sebeta Hawas district, Oromia, Ethiopia," International Journal of Food Sciences and Nutrition, vol. 1, no. 1, pp. 33-47, 2018.

[34] K. Tesfamariam and D. Yilma, "Prevalence of stunting and its associated factors among children under 5 age in Holeta town, West Shoa zone, Oromia region, Ethiopia, 2017," EC Nutrition, vol. 12, no. 2, pp. 90-98, 2017.

[35] B. Teshome, W. Kogi-Makau, Z. Getahun, and G. Taye, "Magnitude and determinants of stunting in children underfive years of age in food surplus region of Ethiopia: the case of west gojam zone," Ethiopian Journal of Health Development, vol. 23, no. 2, 2009.

[36] F. Mesfin, A. Worku, and Y. Birhane, "Prevalence and associated factors of stunting among primary school children in Eastern Ethiopia," Nutrition and Dietary Supplements, vol. 7, pp. 61-68, 2015.

[37] Z. Herrador, L. Sordo, E. Gadisa et al., "Cross-sectional study of malnutrition and associated factors among school aged children in rural and urban settings of Fogera and Libo Kemkem districts, Ethiopia," PLoS One, vol. 9, no. 9, Article ID e105880, 2014.

[38] T. Gultie, E. Sisay, and G. Sebsibie, "Nutritional status and associated factors among orphan children below the age of five years in Gondar city, Ethiopia," Journal of Food and Nutrition Sciences, vol. 2, no. 4, pp. 179-184, 2014.

[39] B. M. Yalew, "Prevalence of malnutrition and associated factors among children age 6-59 months at lalibela town administration, North WolloZone, Anrs, Northern Ethiopia," Journal of Nutritional Disorders \& Therapy, vol. 4, no. 132, pp. 2161-0509, 2014.

[40] D. Amare, A. Negesse, B. Tsegaye, B. Assefa, and B. Ayenie, "Prevalence of undernutrition and its associated factors among children below five years of age in bure town, west Gojjam zone, Amhara national regional state, northwest Ethiopia," Advances in Public Health, vol. 2016, Article ID 7145708, 2016.
[41] A. Woday, Y. Menber, D. Tsegaye, and H. Cherie, "Prevalence of stunting and associated factors among school age children in primary schools of Haik Town, South Wollo Zone, North-Eastern Ethiopia, 2017," Journal of Clinical \& Cellular Immunology, vol. 9, no. 1.

[42] S. Abeway, B. Gebremichael, R. Murugan, M. Assefa, and Y. M. Adinew, "Stunting and its determinants among children aged 6-59 months in northern Ethiopia: a crosssectional study," Journal of Nutrition and Metabolism, vol. 2018, Article ID 1078480, 2018.

[43] USAID, Agency for International Development (USAID), Engine Project under Agreement No. AID-663-A-11-00017. The Contents are the Responsibility of Tufts University and Save the Children and Do Not Necessarily Reflect the Views of USAID or the United States.

[44] World Health Organization, Nutrition Landscape Information System (NLIS): Country Profile 274 Indicators-Interpretation Guide, WHO, Geneva, Switzerland, 2010, https:// apps.who.int/iris/handle/10665/44397.

[45] Central Statistical Agency, Demography and Health Survey Ethiopian Public Health Institute, Central Statistical Agency, Addis Ababa, Ethiopia, 2016.

[46] S. M. Z. Moola, C. Tufanaru, E. Aromataris, K. Sears, and R. Sfetcu, Critical Appraisal Checklist for Analytical CrossSectional Studies, Joanna Briggs Institute, Adelaide, Australia, 2017.

[47] S. Moola, Z. Munn, C. Tufanaru C et al., "Systematic reviews of etiology and risk," in Joanna Briggs Institute Reviewer's Manual, E. Aromataris and Z. Munn, Eds., The Joanna Briggs Institute, Adelaide, Australia, 2017, https:// reviewersmanual.joannabriggs.org/.

[48] M. Egger, G. D. Smith, M. Schneider, and C. Minder, "Bias in meta-analysis detected by a simple, graphical test," $B M J$, vol. 315 , no. 7109, pp. 629-634, 1997.

[49] R. DerSimonian and N. Laird, "Meta-analysis in clinical trials," Controlled Clinical Trials, vol. 7, no. 3, pp. 177-188, 1986.

[50] T. B. Huedo-Medina, J. Sánchez-Meca, F. Marín-Martínez, and J. Botella, "Assessing heterogeneity in meta-analysis: $Q$ statistic or $I^{2}$ index?” Psychological Methods, vol. 11, no. 2, p. $193,2006$.

[51] S. G. Thompson, T. C. Smith, and S. J. Sharp, "Investigating underlying risk as a source of heterogeneity in meta-analysis," Statistics in Medicine, vol. 16, no. 23, pp. 2741-2758, 1997.

[52] J. P. T. Higgins, S. Green, Cochrane Handbook for Systematic Reviews of Interventions Version 6.1, J. P. T. Higgins, J. Thomas, J. Chandler, et al., Wiley, Hoboken, NJ, USA, http://www.training.cochrane.org/handbook.

[53] S. Duval and R. Tweedie, "A nonparametric "trim and fill" method of accounting for publication bias in meta-analysis," Journal of the American Statistical Association, vol. 95, no. 449, pp. 89-98, 2000.

[54] UNICEF, "Improving child nutrition, the achievable imperative for global progress," NCSL Legisbrief, UNICEF, New York, NY, USA, 2013.

[55] S. H. D. Hagos, T. Wolde Hanna, and B. Lindtjørn, "Spatial heterogeneity and risk factors for stunting among children under age five in Ethiopia: a Bayesian geo-statistical model," PLoS One, vol. 12, no. 2, Article ID e0170785, 2017.

[56] K. H. Abate and T. Belachew, "Care and not wealth is a predictor of wasting and stunting of 'The Coffee Kids' of Jimma Zone, southwest Ethiopia," Nutrition and Health, vol. 23, no. 3, pp. 193-202, 2017. 
[57] Y. Fekadu, A. Mesfin, D. Haile, and B. J. Stoecker, "Factors associated with nutritional status of infants and young children in Somali Region, Ethiopia: a cross-sectional study," BMC Public Health, vol. 15, no. 1, p. 846, 2015.

[58] L. Abera, T. Dejene, and T. Laelago, "Magnitude of stunting and its determinants in children aged 6-59 months among rural residents of Damot Gale district; southern Ethiopia," BMC Research Notes, vol. 11, no. 1, p. 557, 2018.

[59] A. A. Abdurahman, K. Mirzaei, A. R. Dorosty, A. Rahimiforoushani, and H. Kedir, "Household food insecurity may predict underweightand wasting among children aged 24-59 months," Ecology of Food and Nutrition, vol. 55, no. 5, pp. 456-472, 2016.

[60] B. Betebo, T. Ejajo, F. Alemseged, and D. Massa, "Household food insecurity and its association with nutritional status of children 6-59 months of age in east Badawacho District, south Ethiopia," Journal of Environmental and Public Health, vol. 2017, Article ID 6373595, 2017.

[61] D. Ali, K. K. Saha, P. H. Nguyen et al., "Household food insecurity is associated with higher child undernutrition in Bangladesh, Ethiopia, and Vietnam, but the effect is not mediated by child dietary diversity," The Journal of Nutrition, vol. 143, no. 12, pp. 2015-2021, 2013.

[62] D. Haile, M. Azage, T. Mola, and R. Rainey, "Exploring spatial variations and factors associated with childhood stunting in Ethiopia: spatial and multilevel analysis," BMC Pediatrics, vol. 16, no. 1, p. 49, 2016.

[63] K. Takele, T. Zewotir, and D. Ndanguza, "Risk factors of morbidity among children under age five in Ethiopia," BMC Public Health, vol. 19, no. 1, pp. 942-949, 2019.

[64] A. G. Wasihun, T. A. Dejene, M. Teferi et al., "Risk factors for diarrhoea and malnutrition among children under the age of 5 years in the Tigray region of Northern Ethiopia," PLoS One, vol. 13, no. 11, Article ID e0207743, 2018.

[65] W. Fentahun, M. Wubshet, and A. Tariku, "Undernutrition and associated factors among children aged 6-59 months in East Belesa district, northwest Ethiopia: a community based cross-sectional study," BMC Public Health, vol. 16, no. 1, p. 506, 2016.

[66] H. Yisak, T. Gobena, and F. Mesfin, "Prevalence and risk factors for under nutrition among children under five at Haramaya district, Eastern Ethiopia," BMC Pediatrics, vol. 15, no. 1, p. 212, 2015.

[67] M. Tessema, T. Belachew, and G. Ersino, "Feeding patterns and stunting during early childhood in rural communities of Sidama, South Ethiopia," The Pan African Medical Journal, vol. 14, no. 1, p. 75, 2013.

[68] A. Gebre, P. Surender Reddy, A. Mulugeta, Y. Sedik, and M. Kahssay, "Prevalence of malnutrition and associated factors among under-five children in pastoral communities of Afar regional state, northeast Ethiopia: a communitybased cross-sectional study," Journal of Nutrition and Metabolism, vol. 2019, Article ID 9187609, 2019.

[69] T. T. Gebru, Y. A. Tesfamichael, M. T. Bitow et al., "Stunting and associated factors among under-five children in Wukro town, Tigray region, Ethiopia: a cross sectional study," BMC Research Notes, vol. 12, no. 1, p. 504, 2019.

[70] K. Berhe, O. Seid, Y. Gebremariam, A. Berhe, and N. Etsay, "Risk factors of stunting (chronic undernutrition) of children aged 6 to 24 months in Mekelle city, Tigray Region, North Ethiopia: an unmatched case-control study," PLoS One, vol. 14, no. 6, Article ID e0217736, 2019.

[71] J. Mekonen, S. Addisu, and H. Mekonnen, "Prevalence and associated factors of chronic undernutrition among under five children in Adama town, Central Ethiopia: a crosssectional study design," BMC Research Notes, vol. 12, no. 1, p. 532, 2019.

[72] A. K. Tekile, A. A. Woya, and G. W. Basha, "Prevalence of malnutrition and associated factors among under-five children in Ethiopia: evidence from the 2016 Ethiopia Demographic and Health Survey," BMC Research Notes, vol. 12, no. 1, p. 391, 2019.

[73] A. Deribew, F. Alemseged, F. Tessema et al., "Malaria and under-nutrition: a community based study among underfive children at risk of malaria, south-west Ethiopia," PLoS One, vol. 5, no. 5, Article ID e10775, 2010.

[74] A. Ma'alin, D. Birhanu, S. Melaku, D. Tolossa, Y. Mohammed, and K. Gebremicheal, "Magnitude and factors associated with malnutrition in children 6-59 months of age in Shinille Woreda, Ethiopian Somali regional state: a cross-sectional study," BMC Nutrition, vol. 2, p. 44, 2016.

[75] H. Darsene, A. Geleto, A. Gebeyehu, and S. Meseret, "Magnitude and predictors of undernutrition among children aged six to fifty nine months in Ethiopia: a cross sectional study," Archives of Public Health, vol. 75, no. 1, p. 29, 2017.

[76] B. Tariku, A. Mulugeta, M. Tsadik, and G. Azene, "Prevalence and risk factors of child malnutrition in community based nutrition program implementing and Nonimplementing districts from south East Amhara, Ethiopia," OALib, vol. 1, no. 3, p. 1, 2014.

[77] K. Mengistu, K. Alemu, and B. Destaw, "Prevalence of malnutrition and associated factors among children aged 6-59 months at hidabu Abote district, north Shewa, Oromia regional state," Journal of Food \& Nutritional Disorders, vol. 1, pp. 1-15, 2013.

[78] E. Agedew and T. Chane, "Prevalence of stunting among children aged 6-23 months in Kemba Woreda, Southern Ethiopia: a community based cross-sectional study," Advances in Public Health, vol. 2015, pp. 1-6, 2015.

[79] B. Yalew, F. Amsalu, and D. Bikes, "Prevalence and factors associated with stunting, underweight and wasting: a community based cross sectional study among children age 6-59 months at Lalibela Town, Northern Ethiopia," Journal of Nutritional Disorders \& Therapy, vol. 4, no. 2, 2014.

[80] A. Tariku, G. A. Biks, T. Derso, M. M. Wassie, and S. M. Abebe, "Stunting and its determinant factors among children aged 6-59 months in Ethiopia," Italian Journal of Pediatrics, vol. 43, no. 1, p. 112, 2017.

[81] M. L. Liben, T. Abuhay, and Y. Haile, "Determinants of child malnutrition among agro pastorals in northeastern Ethiopia: a cross-sectional study," Health Science Journal, vol. 10, no. 4, p. 1, 2016.

[82] T. Derso, A. Tariku, G. A. Biks, and M. M. Wassie, "Stunting, wasting and associated factors among children aged 6-24 months in Dabat health and demographic surveillance system site: a community based cross-sectional study in Ethiopia," BMC Pediatrics, vol. 17, no. 1, p. 96, 2017.

[83] S. K. Dake, F. B. Solomon, T. M. Bobe, H. A. Tekle, and E. G. Tufa, "Predictors of stunting among children 6-59 months of age in Sodo Zuria District, South Ethiopia: a community based cross-sectional study," BMC Nutrition, vol. 5, no. 1, p. 23, 2019.

[84] A. Tariku, H. Woldie, A. Fekadu, A. A. Adane, A. T. Ferede, and S. Yitayew, "Nearly half of preschool children are stunted in Dembia district, Northwest Ethiopia: a community based cross-sectional study," Archives of Public Health, vol. 74, no. 1, p. 13, 2016. 
[85] Z. B. Dessie, M. Fentie, Z. Abebe, T. A. Ayele, and K. F. Muchie, "Maternal characteristics and nutritional status among 6-59 months of children in Ethiopia: further analysis of demographic and health survey," BMC Pediatrics, vol. 19, p. 83, 2019.

[86] A. Gelu, M. Edris, T. Derso, and Z. Abebe, "Undernutrition and associated factors among children aged 6-59 months living in slum areas of Gondar city, northwest Ethiopia: a cross-sectional study," Pediatric Health, Medicine and Therapeutics, vol. 9, p. 81, 2018.

[87] T. Gari, E. Loha, W. Deressa, T. Solomon, and B. Lindtjørn, "Malaria increased the risk of stunting and wasting among youngchildren in Ethiopia: results of a cohort study," PLoS One, vol. 13, no. 1, Article ID e0190983, 2018.

[88] D. Abdissa, "Prevalence of stunting and associated factors among children age between 6-59 months in Dibate district, Metakal zone, Benishangul-Gumuz region, western Ethiopia," MPH thesis, Haramay University, Dire Dawa, Ethiopia, 2018.

[89] Y. Demilew and D. Abie, "Undernutrition and associated factors among 24-36-month-old children in slum areas of Bahir Dar city, Ethiopia," International Journal of General Medicine, vol. 10, p. 79, 2017.

[90] Central Statistical Agency (CSA), Mini Ethiopian Demography and Health Survey, Central Statistical Agency, Ethiopia, 2019.

[91] K. Takele, T. Zewotir, and D. Ndanguz, "Understanding correlates of child stunting in Ethiopia using generalized linear mixed models," BMC Public Health, vol. 19, p. 626, 2019.

[92] D. L. A. Moher, J. Tetzlaff, and D. G. Altman, "Preferred reporting Items for systematic reviews and meta-analyses: the PRISMA statement," PLoS Medicine, vol. 6, no. 7, 2009.

[93] UNICEF/WHO/World Bank Group, Levels and Trends in Child Malnutrition: UNICEF/WHO/World Bank Group Joint Malnutrition Estimates, WHO, Geneva, Switzerland, 2018.

[94] M. De Onis, M. Blössner, and E. Borghi, "Prevalence and trends of stunting among pre-school children, 1990-2020," Public Health Nutrition, vol. 15, no. 1, pp. 142-148, 2012.

[95] UNICEF/WHO/World Bank Group, U-W-W Levels and Trends in Child Malnutrition. UNICEF, WHO, World Bank Group Joint Malnutrition Estimates, WHO, Geneva, Switzerland, 2015.

[96] WHO, Proposed Global Targets for Maternal, Infant and Young Child Nutrition_Globaltargets_Backgroundpaper, WHO, Geneva, Switzerland, 2012.

[97] Federal Ministry of Health, Ethiopian Minister of Health. Health Sector Strategic Plan IV; 2010/11-2014/15, Federal Ministry of Health, Abuja, Nigeria, 2010.

[98] FDRE, "SEQOTA" Declaration: Implementation Plan (2016-2030) World Health Statistics Monitoring Health for the SDGs, WHO, Geneva, Switzerland, 2016.

[99] R. E. Black, C. G. Victora, S. P. Walker et al., "Maternal and child undernutrition and overweight in low-income and middle-income countries," The Lancet, vol. 382, no. 9890, pp. 427-451, 2013.

[100] WHO, "Assessment of differences in linear growth among populations in the WHO Multicentre growth reference study," Acta Paediatrica, vol. 95, no. S450, pp. 56-65, 2006.

[101] J. Ezzati, Determinants of Stunting in East Africa, Université Montpellier, Montpellier, France, 2018.

[102] A. V. A. Abdi, G. T. Yengoh, A. Anyamba, J. Seaquist, C. C. Ummenhofer et al., "The El Niño-La Niña cycle and recent trends in supply and demand of net primary productivity in African drylands," Climatic Change, vol. 138, no. 1-2, pp. 111-125, 2016.

[103] B. Simane, H. Beyene, W. Deressa, A. Kumie, K. Berhane, and J. Samet, "Review of climate change and health in Ethiopia: status and gap analysis," The Ethiopian Journal of Health Development, vol. 30, no. 1, 2016.

[104] OCHA, United Nations' Office for the Coordination of Humanitarian Affairs: Ethiopia, Weekly Humanitarian Bulletin, 2020, http://www.humanitarianresponse.info/en/ operations/ethiopia.

[105] K. Younis, S. Ahmad, and A. Badpa, "Malnutrition: causes and Strategies," Journal of Food Processing \& Technology, vol. 6 , no. 4, p. 434, 2015.

[106] UNICEF, “The state of the WORLD'S children," UNICEF, New York, NY, USA, 1998.

[107] Conceptual Models of Child Malnutrition the ACF Approach in Mental Health and Care Practices, 2012.

[108] UNICEF, The State of the World's Children 2014 in Numbers: Every Child Counts, UNICEF, New York, NY, USA, 2014.

[109] A. O. J. Krishna, J. Lee, H.-Y. Lee, J. M. Perkins, J. Heo et al., "Short-term and long-term associations between household wealth and physical growth: a cross-comparative analysis of children from four low- and middle-income countries," Global Health Action, vol. 8, Article ID 26523, 2015.

[110] S. B. E. Habimana, "Risk factors of stunting among children under 5 years of age in the eastern and western provinces of Rwanda: analysis of Rwanda demographic and health survey 2014/2015," Pediatric Health, Medicine and Therapeutics, vol. 10, pp. 115-130, 2019.

[111] R. Kim, I. Mejía-Guevara, D. J. Corsi, V. M. Aguayo, and S. V. Subramanian, "Relative importance of 13 correlates of child stunting in South Asia: insights from nationally representative data from Afghanistan, Bangladesh, India, Nepal, and Pakistan," Social Science \& Medicine, vol. 187, pp. 144-154, 2017.

[112] M. R. D. B. Angdembe, K. Bhattarai, and S. Karn, "Trends and predictors of inequality in childhood stunting in Nepal from 1996 to 2016," International Journal for Equity in Health, vol. 18, no. 1, pp. 1-17, 2019.

[113] N. B. J. Fenske, T. Hothorn, and E. A. Rehfuess, "Understanding child stunting in India: a comprehensive analysis of socio-economic, nutritional and environmental determinants using additive quantile regression," PLoS One, vol. 8, no. 11, Article ID e0078692, 2013.

[114] R. M. A. M. Mian, P. A. Ferroni, and P. Underwood, "The nutritional status of school-aged children in an urban squatter settlement in Pakistan," Pakistan Journal of $\mathrm{Nu}$ trition, vol. 1, no. 3, pp. 121-123, 2002.

[115] G. R. S. Veiga, H. S. Ferreira, A. L. Sawaya, J. Calado, and T. M. M. T. Florêncio, "Dyslipidaemia and undernutrition in children from impoverished areas of maceió, state of Alagoas, Brazil," International Journal of Environmental Research and Public Health, vol. 7, no. 12, pp. 4139-4151, 2010.

[116] Headey and D. Derek, "An analysis of trends and determinants of child under nutrition in Ethiopia, 2000-2011," International Food Policy Research Institute, Washington, DC, USA, 2014, http://ebrary.ifpri.org/cdm/ref/collection/ p15738coll2/id/128896.

[117] S. Biadgilign, A. Shumetie, and H. Yesigat, "Does economic growth reduce childhood under nutrition in Ethiopia," PLoS One, vol. 11, no. 8, Article ID e0160050, 2016.

[118] L. R. Buismana, E. Van de Poel, O. O’Donnellb, and E. van Doorslae, "What explains the fall in child stunting in 
Sub-Saharan Africa?" Population Health, vol. 8, Article ID 100384, 2019.

[119] M. Saaka and S. Z. Galaa, "Relationships between wasting and stunting and their concurrent occurrence in Ghanaian preschool children," Journal of Nutrition and Metabolism, vol. 2016, Article ID 4654920, 2016.

[120] UNICEF Communication UDo, Tracking Progress on Child and Maternal Nutrition: A Survival and Development Priority, UNICEF, New York, NY, USA, 2009.

[121] R. Martorell and A. Zongrone, Intergenerational Influences on Child Growth and Undernutrition Paediatric and Perinatal Epidemiology, vol. 26, no. 1, 2012.

[122] FMoH Situation, "Analysis of the nutrition sector in Ethiopia 2000-2015," in Ethiopian Federal Ministry of Health U, and European Commission DelegationAddis Ababa, Ethiopia, 2016.

[123] S. H. Gebreyesus, T. Lunde, D. H Mariam, T. Woldehanna, and B. Lindtjørn, "Is the adapted Household Food Insecurity Access Scale (HFIAS) developed internationally to measure food insecurity valid in urban and rural households of Ethiopia?" BMC Nutrition, vol. 1, no. 1, p. 2, 2015.

[124] I. P. C. Outes, "Catching up from early nutritional deficits? evidence from rural Ethiopia," Economics and Human Biology, vol. 11, no. 14863, 2013.

[125] J. H. J. Behrman, "An evaluation of the impact of PROGRESA on child height," International Food Policy Research Institute, Washington, DC, USA, 2001.

[126] P. Gertler, "Do conditional cash transfers improve child health? evidence from PROGRESA's control randomized experiment," The American Economic Review, vol. 94, pp. 336-341, 2004.

[127] J. B. J. Hoddinott, J. A. Maluccio, P. Melgar, A. R. Quisumbing, M. Ramirez-Zea et al., "Adult consequences of growth failure in early childhood," The American Journal of Clinical Nutrition, vol. 98, pp. 1170-1178, 2013.

[128] J. S. E. Hoddinott, "The impact of PROGRESA on food consumption," Economic Development and Cultural Change, vol. 53, no. 3761, 2004. 